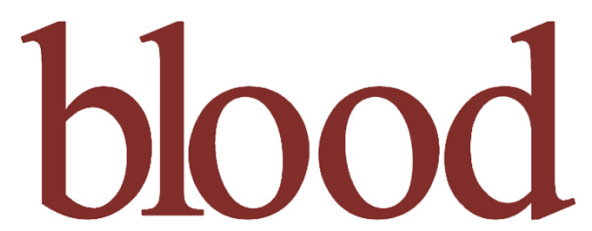

2009 114: 380-393

Prepublished online April 21, 2009;

doi:10.1182/blood-2008-10-182758

\title{
The histone deacetylase inhibitors LAQ824 and LBH589 do not require death receptor signaling or a functional apoptosome to mediate tumor cell death or therapeutic efficacy
}

Leigh Ellis, Michael Bots, Ralph K. Lindemann, Jessica E. Bolden, Andrea Newbold, Leonie A. Cluse, Clare L. Scott, Andreas Strasser, Peter Atadja, Scott W. Lowe and Ricky W. Johnstone

Updated information and services can be found at:

http://bloodjournal.hematologylibrary.org/content/114/2/380.full.html

Articles on similar topics can be found in the following Blood collections

Lymphoid Neoplasia (1320 articles)

Information about reproducing this article in parts or in its entirety may be found online at:

http://bloodjournal.hematologylibrary.org/site/misc/rights.xhtml\#repub_requests

Information about ordering reprints may be found online at:

http://bloodjournal.hematologylibrary.org/site/misc/rights.xhtml\#reprints

Information about subscriptions and ASH membership may be found online at:

http://bloodjournal.hematologylibrary.org/site/subscriptions/index.xhtml

Blood (print ISSN 0006-4971, online ISSN 1528-0020), is published weekly by the American Society of Hematology, 2021 L St, NW, Suite 900,

Washington DC 20036.

Copyright 2011 by The American Society of Hematology; all rights reserved.

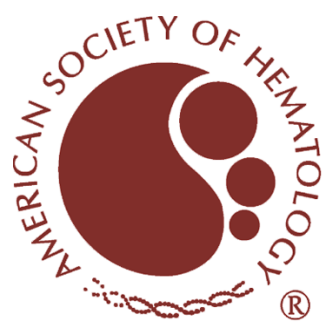




\title{
The histone deacetylase inhibitors LAQ824 and LBH589 do not require death receptor signaling or a functional apoptosome to mediate tumor cell death or therapeutic efficacy
}

\author{
Leigh Ellis, ${ }^{1,2}$ Michael Bots, ${ }^{1}$ Ralph K. Lindemann, ${ }^{1}$ Jessica E. Bolden, ${ }^{1}$ Andrea Newbold,${ }^{1}$ Leonie A. Cluse, ${ }^{1}$ Clare L. Scott, ${ }^{3}$ \\ Andreas Strasser, ${ }^{3}$ Peter Atadja, ${ }^{4}$ Scott W. Lowe,${ }^{5}$ and Ricky W. Johnstone ${ }^{1,6}$ \\ ${ }^{1}$ Cancer Therapeutics Program, Gene Regulation Laboratory, Peter MacCallum Cancer Centre, Trescowthick Research Laboratories, East Melbourne, Australia; \\ ${ }^{2} \mathrm{John}$ Curtin School of Medical Research, Australian National University, Canberra, Australia; ${ }^{3}$ Walter and Eliza Hall Institute, Melbourne, Australia; ${ }^{4}$ Novartis \\ Institutes for BioMedical Research, Cambridge, MA; ${ }^{5}$ Cold Spring Harbor Laboratory, Cold Spring Harbor, NY; and 6 University of Melbourne, Parkville, Australia
}

\begin{abstract}
LAQ824 and LBH589 (panobinostat) are histone deacetylase inhibitors (HDACi) developed as cancer therapeutics and we have used the $\mathrm{E}_{\mu}-m y c$ lymphoma model to identify the molecular events required for their antitumor effects. Induction of tumor cell death was necessary for these agents to mediate therapeutic responses in vivo and both HDACi engaged the intrinsic apoptotic cascade that did not require p53. Death receptor pathway blockade had no effect on the therapeutic
\end{abstract}

activities of LAQ824 and LBH589; however, overexpression of $\mathrm{Bcl}-2$ or $\mathrm{Bcl}-\mathrm{X}_{\mathrm{L}}$ protected lymphoma cells from HDACi-induced killing and suppressed their therapeutic activities. Deletion of Apaf-1 or Caspase-9 delayed HDACi-induced lymphoma killing in vitro and in vivo, associated with suppression of many biochemical indicators of apoptosis, but did not provide long-term resistance to these agents and failed to inhibit their therapeutic activities. E $\mu$-myc lymphomas lacking a functional apopto- some displayed morphologic and biochemical features of autophagy after treatment with LAQ824 and LBH589, indicating that, in the absence of a complete intrinsic apoptosis pathway involving apoptosome formation, these HDACi can still mediate a therapeutic response. Our data indicate that damage to the mitochondria is the key event necessary for LAQ824 and LBH589 to mediate tumor cell death and a robust therapeutic response. (Blood. 2009;114:380-393)

\section{Introduction}

There is growing evidence that altered gene expression, governed by epigenetic changes, plays a fundamental role in cancer onset and progression.1,2 Consequently, compounds, such as 5-aza-2'deoxycytidine that inhibit DNA methyltransferases and induce genome-wide hypomethylation, and histone deacetylase inhibitors (HDACi), have been developed and found to exert anticancer activity both in the laboratory and in the clinic., ${ }^{2,3}$ A large number of HDACi have been developed that differ in chemical structure, and they inhibit the enzymatic activity of class I, II, and IV HDACs with various efficiencies. ${ }^{3}$ LAQ824 and LBH589 are members of the hydroxamic acid class of HDACi that show broad enzyme inhibitory activity in the low nanomolar range ${ }^{4}$ and have progressed through preclinical development into early-phase clinical trials. $^{5,6}$ These HDACi can have diverse anticancer activities, including induction of tumor cell apoptosis, ${ }^{7-11}$ inhibition of cell-cycle progression, ${ }^{12,13}$ and suppression of angiogenesis. ${ }^{14,15}$ Both LAQ824 and LBH589 are particularly effective in killing primary leukemia and lymphoma cells and established tumorderived cell lines in vitro, ${ }^{7-11,13}$ and studies using xenotransplantation tumor models have demonstrated therapeutic efficacy in vivo. . $^{7,12,14,15}$

Determining whether HDACi-mediated tumor cell apoptosis is important for the therapeutic activity of the drugs remains an important unanswered question. Moreover, although LAQ824 and LBH589 have been shown to induce morphologic and biochemical changes associated with apoptosis, exactly how these drugs trigger

Submitted October 22, 2008; accepted March 31, 2009. Prepublished online as Blood First Edition paper, April 21, 2009; DOI 10.1182/blood-2008-10-182758.

The online version of this article contains a data supplement. the apoptotic pathway remains to be elucidated. LAQ824 and LBH589 both inhibit the activity of HDAC6. This results in hyperacetylation of Hsp90 and subsequent polyubiquitylation and proteasomal degradation of client proteins, including Bcr-Abl, AKT, c-Raf, and FLT-3, ${ }^{9-11}$ but whether this effect is directly related to the proapoptotic activities of the compounds remains unclear. Other apoptosis-related events, such as activation of the death receptor pathway through transcriptional induction of tumor necrosis factor-related apoptosis-inducing ligand (TRAIL) receptors DR4 and DR5, ${ }^{16}$ down-regulation and/or degradation of prosurvival proteins (XIAP, Mcl-1, Bcl-2, Bcl-XL), production of reactive oxygen species and the lipid second messenger ceramide, ${ }^{17}$ and up-regulation of the apoptosome proteins caspase-9 and Apaf-1, ${ }^{18}$ have been reported after treatment of tumor cell lines with LAQ824 and/or LBH589.

The focus of this study was to identify the proteins and pathways involved in LAQ824- and LBH589-induced tumor cell killing and to determine the relationship between the ability of these agents to directly kill their tumor targets and mediate a therapeutic benefit. To do this, we used the $\mathrm{E} \mu-m y c$ transgenic mouse model of pre-B/B-cell lymphoma. ${ }^{19}$ This model is readily tractable and allows genetic manipulation by cross-breeding and retroviral transduction to produce "compound mutant" lymphomas that can be used in vitro and in vivo to identify molecular pathways important for a given drug to have an anticancer effect. ${ }^{20,21}$ Importantly, therapy studies using E $\mu$-myc lymphomas can be

The publication costs of this article were defrayed in part by page charge payment. Therefore, and solely to indicate this fact, this article is hereby marked "advertisement" in accordance with 18 USC section 1734.

(C) 2009 by The American Society of Hematology 
performed in immunocompetent C57BL/6 mice, thereby allowing consideration of potential interactions between HDACi and the host immune system. Using this model, we show a direct correlation between the induction of tumor cell death by LAQ824 and LBH589 in vitro and therapeutic efficacy in vivo. Both LAQ824 and LBH589 induced morphologic and biochemical changes commonly associated with apoptosis, and we show that these agents preferentially activated the intrinsic (mitochondrial) apoptotic pathway to kill their tumor targets. Interestingly, E $\mu-m y c$ lymphomas lacking a functional apoptosome, resulting from deletion of the apaf-1 or caspase-9 genes, showed a delayed cell death but still lost their clonogenic capacity after exposure to LAQ824 and LBH589, concomitant with loss of mitochondrial membrane integrity. These cells did not display caspase activation, DNA fragmentation, or perturbation of the plasma membrane. Interestingly, E $\mu$-myclapaf-1 $1^{-1-}$ lymphomas treated with LAQ824 or LBH589 displayed morphologic and biochemical features consistent with autophagy, indicating that, in the absence of a functional intrinsic apoptotic cascade, HDACi can kill tumor cells through alternative mechanisms. Importantly, Apaf-1-deficient E $\mu-m y c$ lymphomas remained sensitive to LAQ824 and LBH589 in vivo, indicating that loss of viability, primarily through induction of apoptosis via the intrinsic apoptotic pathway but also through cell death events mediated downstream of mitochondrial membrane damage, produces therapeutic efficacy in response to these compounds.

\section{Methods}

\section{Cell culture and reagents}

$\mathrm{E} \mu-m y c, \mathrm{E} \mu-m y c / b c l-2, \mathrm{E} \mu-m y c / b c l-X_{L}, \mathrm{E} \mu-m y c / p 53^{-/-}, \mathrm{E} \mu-m y c / t r a i l^{-1-}$, $\mathrm{E} \mu-m y c l a p a f-1^{-1-}, \mathrm{E} \mu-m y c /$ caspase- $^{-1-}, \mathrm{E} \mu-$ myclarf $^{-1-}$, and $\mathrm{E} \mu-m y c l$ CrmA lymphomas were developed as previously described. ${ }^{19,21-23} \mathrm{E} \mu-m y c$ lymphomas were cultured in 6-well plates (Greiner Bio-One) in the high-glucose version of Dulbecco modified Eagle medium supplemented with $10 \%$ fetal calf serum, penicillin/streptomycin, $0.1 \mathrm{mM} \mathrm{L}$-asparagine, and $50 \mu \mathrm{M}$ 2-mercaptoethanol. LAQ824 and LBH589 were dissolved in dimethyl sulfoxide for the preparation of stock solutions (10 mM). Tetramethylrhodamine ethyl ester (TMRE) was purchased from Invitrogen. Etoposide was obtained from the Peter MacCallum Cancer Center hospital pharmacy (East Melbourne, Australia). Fluoroisothiocyanate (FITC)-VAD was purchased from Promega. All other chemicals were from SigmaAldrich. The antibodies against acetylated histone $\mathrm{H} 3$ were purchased from Upstate Biotechnology. Anti-LC3 (clone 2G6) and anti-p42 ERK (clone 3A7) monoclonal antibodies were obtained from Nanotools and Cell Signaling Technology, respectively. Anti-Bcl-2 and anti-CrmA antibodies were from BD Biosciences, and anti-Bcl- $\mathrm{X}_{\mathrm{L}}$ was purchased from Santa Cruz Biotechnology.

\section{In vitro cell death assays}

E $\mu$-myc lymphoma cells $\left(5 \times 10^{5}\right.$ cells $\left./ \mathrm{mL}\right)$ were incubated in the presence of the indicated compounds for 20 hours in $1 \mathrm{~mL}$ cell culture medium in 24-well plates (Greiner Bio-One). Viability of cells was measured by propidium iodide (PI) uptake, annexin V staining, fluorescein isothiocyanate vincristine-doxorubicindexamethasone staining, cell-cycle analysis, or TMRE staining and performed as described. ${ }^{21} P$ values were calculated using a 2-way $t$ test; $95 \%$ confidence intervals were calculated using MedCalc software, version 8.0.2.0.

\section{Clonogenic survival assays}

Cells were treated overnight with LAQ824 or LBH589, and $8 \times 10^{2}$ cells were then added to $1.5 \mathrm{~mL}$ molten soft agar (20\% fetal bovine serum $/ 0.3 \%$ agar in media) and $500 \mu \mathrm{L}$ of this mixture plated in triplicate in a 24-well, flat-bottom plate (BD Biosciences). Agar was allowed to set for 30 minutes at room temperature before overlaying with $1 \mathrm{~mL}$ of medium. Plates were incubated in a humidified $37^{\circ} \mathrm{C}$ incubator for 7 to 12 days. Colonies were counted using an inverted microscope (Opelco).

\section{Mice}

Six- to 8-week-old C57BL/6 mice were used for in vivo apoptosis assays and therapy studies. The Peter MacCallum Cancer Center Animal Ethics Committee approved all mouse protocols used in this study. Polymerase chain reaction-based genotyping and Western blotting analysis were used to validate lymphoma genotypes (data not shown).

\section{In vivo apoptosis assays}

For in vivo apoptosis assays, C57BL/6 mice were injected with $\mathrm{E} \mu-m y c$ lymphoma cells $\left(5 \times 10^{5}\right.$ cells per animal), and after 10 to 15 days when lymph nodes became well palpable, LAQ824 $(75 \mathrm{mg} / \mathrm{kg})$ or LBH589 $(80 \mathrm{mg} / \mathrm{kg})$ was administered intravenously. After the indicated time points, mice were killed and cells were harvested from brachial lymph nodes for fluorescence-activated cell sorter (FACS)-based assays to analyze apoptosis signaling..$^{21}$

To assess therapeutic efficacy of LAQ824 and LBH589, C57BL/6 mice were injected with $\mathrm{E} \mu$-myc lymphoma cells of the indicated genotypes intravenously $\left(5 \times 10^{5}\right.$ cells per animal). Peripheral white blood cell (WBC) counts were monitored every 2 to 3 days until they exceeded $13 \times 10^{9}$ cells $/ \mu \mathrm{L}$ (Sysmex Hematology Analyzer K-1000, Sysmex) and LAQ824 (75 mg/kg) injected intravenously every 5 days (4 injections) or LBH589 $(80 \mathrm{mg} / \mathrm{kg}$ ) injected intravenously every 7 days (3 injections). Statistical analyses were performed using a Student $t$ test. We have previously determined that this regimen represented the maximum tolerated dose in lymphoma-bearing mice (data not shown). Mice in the control cohort received the corresponding amount of $10 \%$ lactic acid/water 5\% dextrose (D5W). Cohorts consisted of 8 to 11 mice each, and peripheral WBC counts and body weights were recorded weekly. On signs of major distress or when lymphomas were relapsing as indicated by enlarged brachioaxial lymph nodes, mice were killed and subjected to postmortem analysis. For analysis of therapeutic efficacy, tumor-induced mortality "events" were recorded. Kaplan-Meier analysis was performed, and comparisons made using the Mann-Whitney U test (MedCalc software, version 8.0.2.0).

\section{Histology and transmission electron microscopy}

Paraffin-embedded sections $(4 \mu \mathrm{m})$ from $10 \%$ neutral buffered formalinfixed lymph nodes were stained with hematoxylin and eosin (kindly performed by the Peter MacCallum Cancer Center Histology core facility) to evaluate nuclear apoptotic morphology of E $\mu$-myc lymphoma cells in situ. TdT-mediated dUTP nick end-labeling (TUNEL) staining was performed using the Apoptag Peroxidase In Situ Apoptosis Detection Kit (Chemicon International) kit following the manufacturer's instructions. Acetylated histone H3 was detected using a Dako Autostainer Plus (Dako North America). Samples were incubated with antiacetyl histone H3 antibodies (1:1200; Upstate Biotechnology) and then incubated with EnVision + System HRP anti-rabbit IgG antibodies (Dako North America). Sections were counterstained using a hematoxylin solution. Images from sections were recorded with a Zeiss Axioskop2 microscope (Carl Zeiss) and a $40 \times$ lens using the SPOT Advanced image acquisition software (version 4.1, Diagnostic Instruments).

For transmission electron microscopy (TEM) analysis, cells were washed twice in phosphate-buffered saline (PBS) and fixed in $0.08 \mathrm{M}$ Sorensen phosphate buffer ( $\mathrm{pH}$ 7.4) containing $2.5 \%$ glutaraldehyde and $2 \%$ paraformaldehyde for 2 hours at room temperature. After fixation, cells were washed in PBS and embedded in agarose. Sections $(60-80 \mathrm{~nm})$ were stained with lead citrate and uranyl acetate and examined under a Jeol 1011 electron microscope (Joel Australasia). Images were taken using a MegaView III Digital camera with analySIS software (Olympus Soft Imaging Systems). 
From bloodjournal.hematologylibrary.org at AUSTRALIAN NATL UNIV on February 18, 2013. For personal use

A

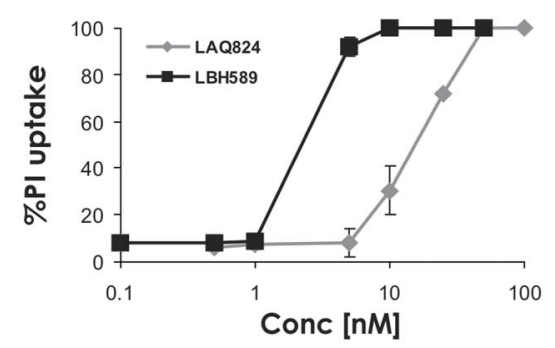

C
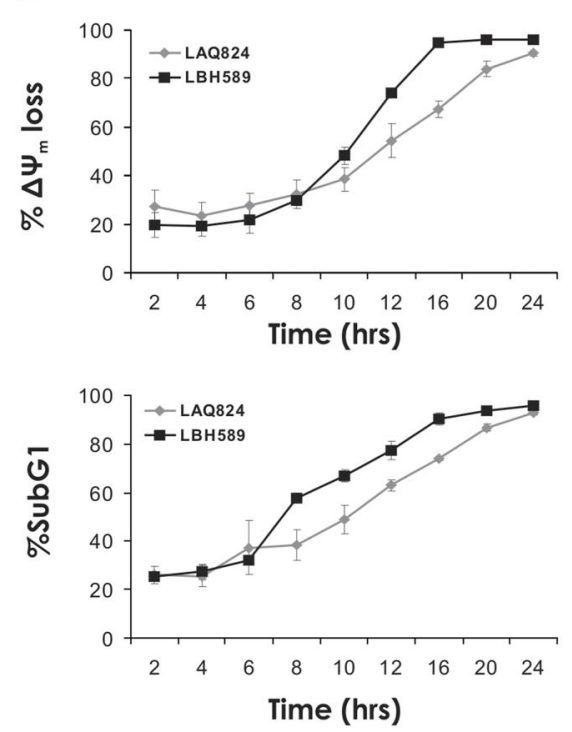

B

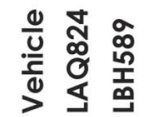

Ac-H3

B-actin

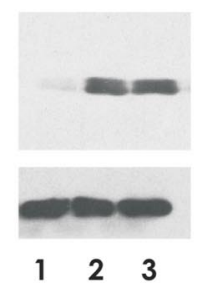

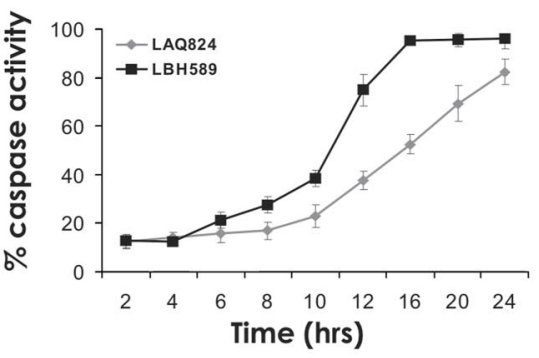

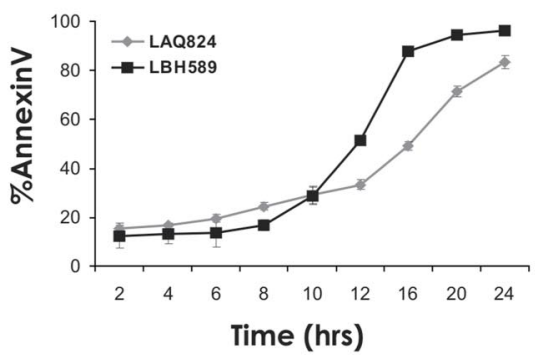

LAQ824

D

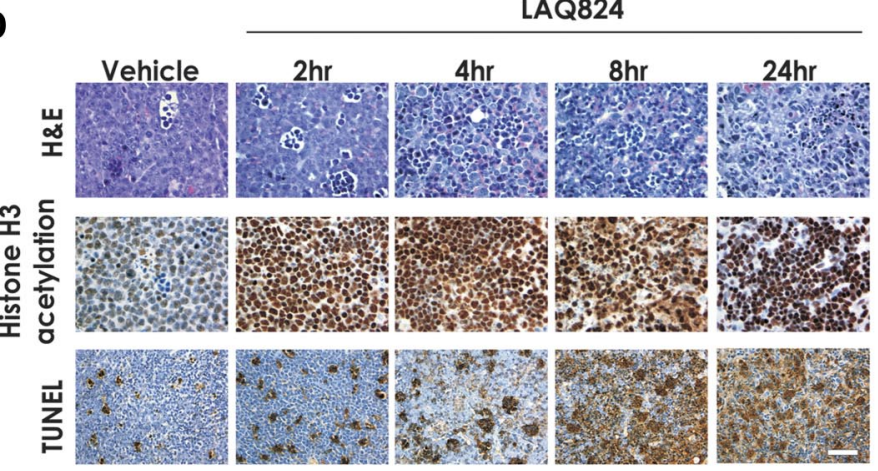

LBH589

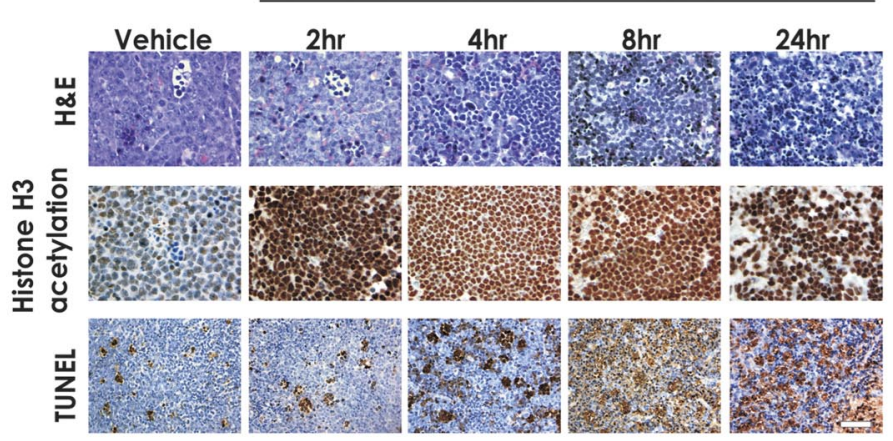

$\mathbf{E}$

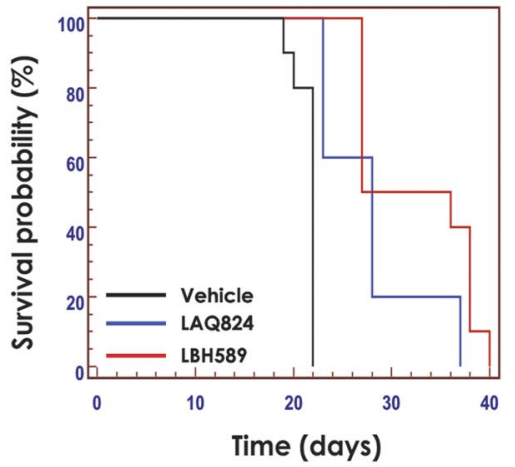

$\mathbf{F}$

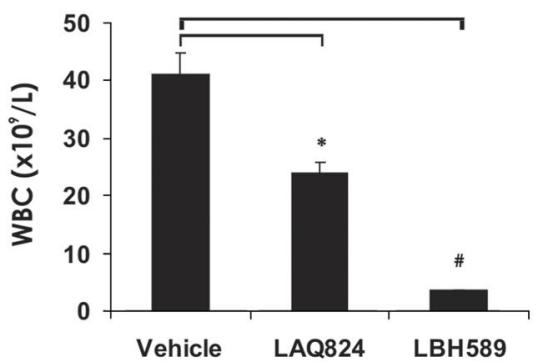




\section{Western blot analysis}

Cells were washed twice in PBS and lysed in Triton X-100 lysis buffer (1\% Triton X-100, $20 \mathrm{mM}$ Tris, $\mathrm{pH} 7.5,150 \mathrm{mM} \mathrm{NaCl}, 2 \mathrm{mM}$ ethylenediaminetetraacetic acid, $10 \%$ glycerol), containing a cocktail of protease inhibitors (Sigma-Aldrich). Proteins were separated by sodium dodecyl sulfatepolyacrylamide gel electrophoresis (15\%) and transferred onto polyvinylidene difluoride membranes (Millipore). Membranes were blocked with 5\% nonfat milk in Tris-buffered saline/0.1\% Tween-20 for 2 hours at room temperature and incubated overnight with primary antibodies. Membranes were developed using horseradish peroxidase-coupled rabbit anti-mouse IgG (Dako North America) and enhanced chemiluminescence (GE Healthcare).

\section{Results}

\section{E $\mu-m y c$ lymphomas undergo apoptosis when exposed to LAQ824 and LBH589}

E $\mu$-myc lymphomas cultured ex vivo were exposed for 24 hours to increasing concentrations of the HDACi LAQ824 and LBH589 and plasma membrane integrity assessed by uptake of PI. As shown in Figure 1A, low-nanomolar concentrations of LBH589 and LAQ824 were sufficient to kill E $\mu$-myc lymphoma cells, as determined by PI uptake. The concentration of HDACi resulting in $70 \%$ cell death $\left(\mathrm{LD}_{70}\right)$ was $25 \mathrm{nM}$ for LAQ824 and $4 \mathrm{nM}$ for LBH589. These concentrations of LAQ824 and LBH589 were sufficient to induce comparable levels of hyperacetylation of histone H3 within a 2-hour incubation (Figure 1B). We next assessed the biochemical changes that occurred after treatment of E $\mu$-myc lymphoma cells with LAQ824 or LBH589. E $\mu-m y c$ lymphomas treated with LAQ824 or LBH589 displayed hallmark features of apoptosis, including loss of mitochondrial membrane potential $\left(\Delta \psi_{\mathrm{m}}\right)$, caspase activation, DNA fragmentation, and cell surface exposure of phosphatidylserine (Figure 1C) in a timedependent manner. In all cases, LBH589 was a more potent inducer of apoptosis than LAQ824.

\section{Therapeutic activity of LAQ824 and LBH589 against $\mathrm{E}_{\mu-m y c}$ lymphoma}

To determine whether LAQ824 and LBH589 were capable of killing E $\mu-m y c$ cells in vivo, C57BL/6 mice bearing an $\mathrm{E} \mu-m y c$ lymphoma were treated with LAQ824, LBH589, or vehicle for various times. Lymph nodes were harvested at 2, 4, 8, and 24 hours and drug activity assessed by histologic examination (Figure 1D). Both HDACi induced rapid and extensive apoptosis in $\mathrm{E} \mu-m y c$ lymphoma cells within whole animals, as determined by TUNEL staining and morphologic changes associated with apoptosis, including cell shrinkage and chromatin condensation. Induction of tumor cell apoptosis by LAQ824 and LBH589 was preceded by hyperacetylation of histone $\mathrm{H} 3$, and consistent with the data

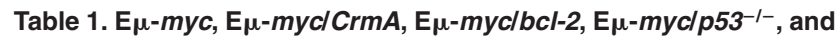
E $\mu$-myclapaf-1 $1^{-1-}$ lymphomas, different from those used in data presented in Figures 1 through 5, were injected into C57BL/6 mice, and the therapeutic efficacy of LAQ824 and LBH589 was assessed in tumor-bearing mice

\begin{tabular}{|c|c|c|}
\hline E $\mu-m y c$ lymphoma & $\begin{array}{l}\text { Median survival, } \\
\qquad \mathrm{d}(P)\end{array}$ & $\begin{array}{c}\text { WBC, } \times 10^{9} / \mathrm{mL} \\
\text { mean } \pm \mathrm{SE}\end{array}$ \\
\hline \multicolumn{3}{|l|}{$\mathrm{E}_{\mu}-m y c \# 2$} \\
\hline Vehicle & 22 & $38.7 \pm 1.3$ \\
\hline LAQ824 & $28(.003)$ & $9.9 \pm 1.5$ \\
\hline LBH589 & $31.5(<.001)$ & $3.4 \pm 0.3$ \\
\hline \multicolumn{3}{|l|}{$\mathrm{E}_{\mu}-\mathrm{m} y c / C r m A \# 2$} \\
\hline Vehicle & 18 & $19.4 \pm 0.8$ \\
\hline LAQ824 & $22(<.001)$ & $10.8 \pm 2.7$ \\
\hline LBH589 & $26.5(<.001)$ & $11.0 \pm 1.8$ \\
\hline \multicolumn{3}{|l|}{$\mathrm{E}_{\mu-m y c / b c l-2 \# 2}$} \\
\hline Vehicle & 21 & $52.6 \pm 11.2$ \\
\hline LAQ824 & 19 & $41.0 \pm 7.4$ \\
\hline LBH589 & 19 & $23.4 \pm 7.5$ \\
\hline \multicolumn{3}{|l|}{ 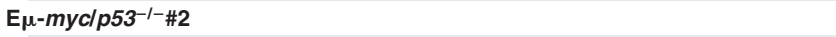 } \\
\hline Vehicle & 20.5 & $19.6 \pm 1.5$ \\
\hline LAQ824 & $23.5(.002)$ & $12.5 \pm 3.2$ \\
\hline LBH589 & $36.5(<.001)$ & $6.0 \pm 0.8$ \\
\hline \multicolumn{3}{|l|}{ E $\mu-$ myclapaf-1-1-\#2 } \\
\hline Vehicle & 29 & $48.1 \pm 4.1$ \\
\hline LAQ824 & $44(.002)$ & $16.4 \pm 2.6$ \\
\hline LBH589 & $47.5(.004)$ & $2.5 \pm 0.3$ \\
\hline
\end{tabular}

Data represent the median survival times derived from Kaplan-Meier curves and white blood cell (WBC) counts taken 3 days after treatment with vehicle, LAQ824, or LBH589 (3 mice per data point).

obtained in vitro (Figure 1B), this change was apparent as early as 2 hours after treatment. Taken together, these data demonstrate that LAQ824 and LBH589 are capable of inducing histone hyperacetylation and apoptosis in $\mathrm{E} \mu-m y c$ lymphoma cells in vivo.

To determine whether the apoptosis-inducing effects of LBH589 and LAQ824 translated into a therapeutic response, C57BL/6 mice were given transplants of an $\mathrm{E} \mu-m y c$ lymphoma and treatment with LAQ824, LBH589, or vehicle commenced when WBC counts reached a pathologic threshold $\left(>13 \times 10^{9}\right.$ cells $\left./ \mu \mathrm{L}\right)$. Mice were administered intravenously with LAQ824 or LBH589, and the treated mice showed a statistically significant increase in median survival time compared with those mice injected with vehicle (Figure 1E, median survival vehicle $=22$ days; median survival LAQ824 $=28$ days, $P=.001$; median survival LBH589 $=34$ days, $P<.001)$. Consistent with the increase in survival seen after treatment of lymphoma-bearing mice with LAQ824 and LBH589, both agents caused a statistically significant decrease in WBC counts when assessed 3 days after the first injection of drug, with WBC numbers restored to near-normal levels by LBH589 (Figure $1 \mathrm{~F})$. To ensure that the observed in vivo effects of LAQ824 and LBH589 administration were not restricted to a single tumor, similar studies yielding comparable results were performed with an

Figure 1. The HDACi LAQ824 and LBH589 induce cell death in E $\mu$-myc lymphomas both in vitro and in vivo. (A) E $\mu$-myc lymphoma cells were incubated for 24 hours with the indicated concentrations of LAQ824 or LBH589. Cell viability was determined by the uptake of PI and FACS analysis. (B) Whole cell lysates were prepared from $\mathrm{E} \mu$-myc lymphoma cells that had been treated for 2 hours with vehicle, LAQ824 ( $25 \mathrm{nM})$, or LBH589 (4 nM). Western blot analysis was performed with antibodies specific for acetylated histone H3. Equivalent protein loading was confirmed by probing for $\beta$-actin. (C) E $\mu$-myc lymphomas were treated with LAQ824 (25 nM) or LBH589 (4 nM) for the indicated times, and apoptosis was assessed by flow cytometric analysis of $\Delta \psi \mathrm{m}$, caspase activation, presence of cells with $<2 n$ DNA content (sub $\mathrm{G}_{1}$ ), and surface exposure of phosphotidylserine (annexin V staining). Each dose or time point represents the mean value of 3 individual experiments \pm SE. (D) C57BL/6 mice bearing palpable E $\mu-m y c$ lymphoma cells were treated intravenously with LAQ824 $(75 \mathrm{mg} / \mathrm{kg})$ or LBH589 (80 mg/kg), and lymph nodes were harvested at the indicated times. Histologic sections were assessed by hematoxylin and eosin staining (top panel), immunohistochemistry using antibodies to acetyl histone $\mathrm{H} 3$ (middle panel), and TUNEL staining (bottom panel). Each time point is representative of an individual mouse. (E) C57BL/6 mice bearing an $\mathrm{E} \mu-$ myc lymphoma were treated with vehicle (200 $\mu \mathrm{L} 10 \%$ lactic acid/D5W; $n=10), \mathrm{LAQ} 824$ (75 mg/kg; $n=10)$, or LBH589 (80 mg/kg; $n=10$ ). Kaplan-Meier survival curves of mice treated with vehicle (black line), LAQ824 (blue line), or LBH589 (red line) are shown. (F) WBC counts of mice bearing an E $\mu$-myc lymphoma were taken 3 days after treatment with vehicle, LAQ824, or LBH589. Each point represents the mean value of 3 individual mice $\pm \mathrm{SE}\left({ }^{*} P=.01 ; \# P=.004\right)$. 
A E $\mathrm{A}-\mathrm{myc} / \mathrm{CrmA} \quad$ B

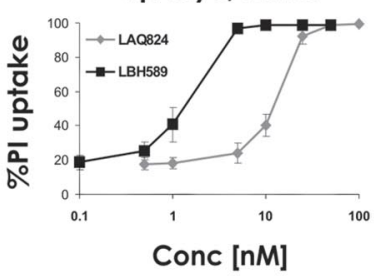

EM-myc/TRAIL-/-

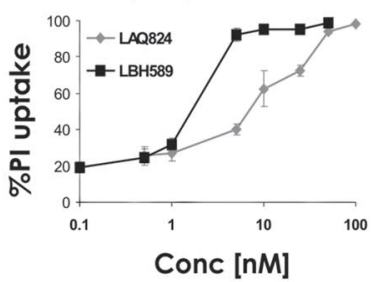

C

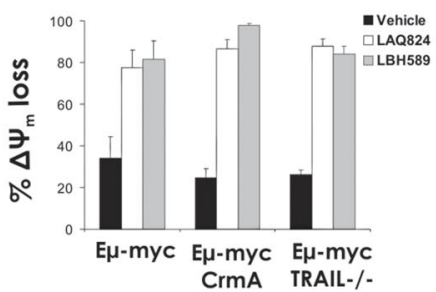

E

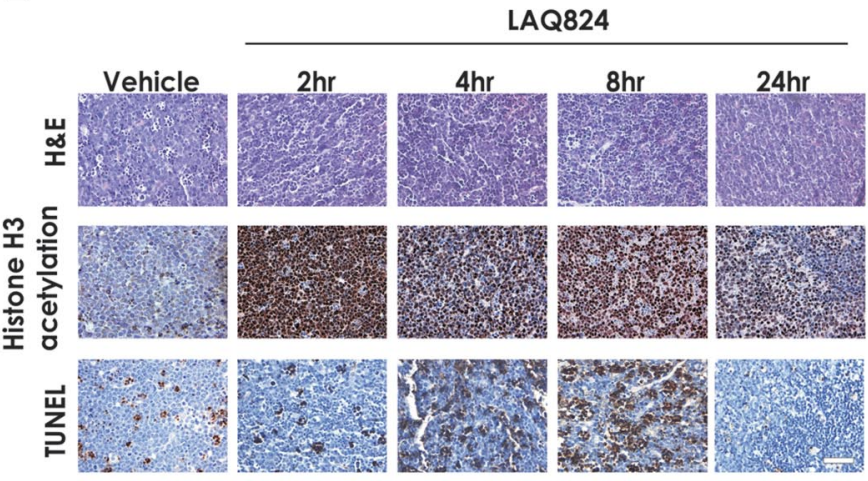

LBH589
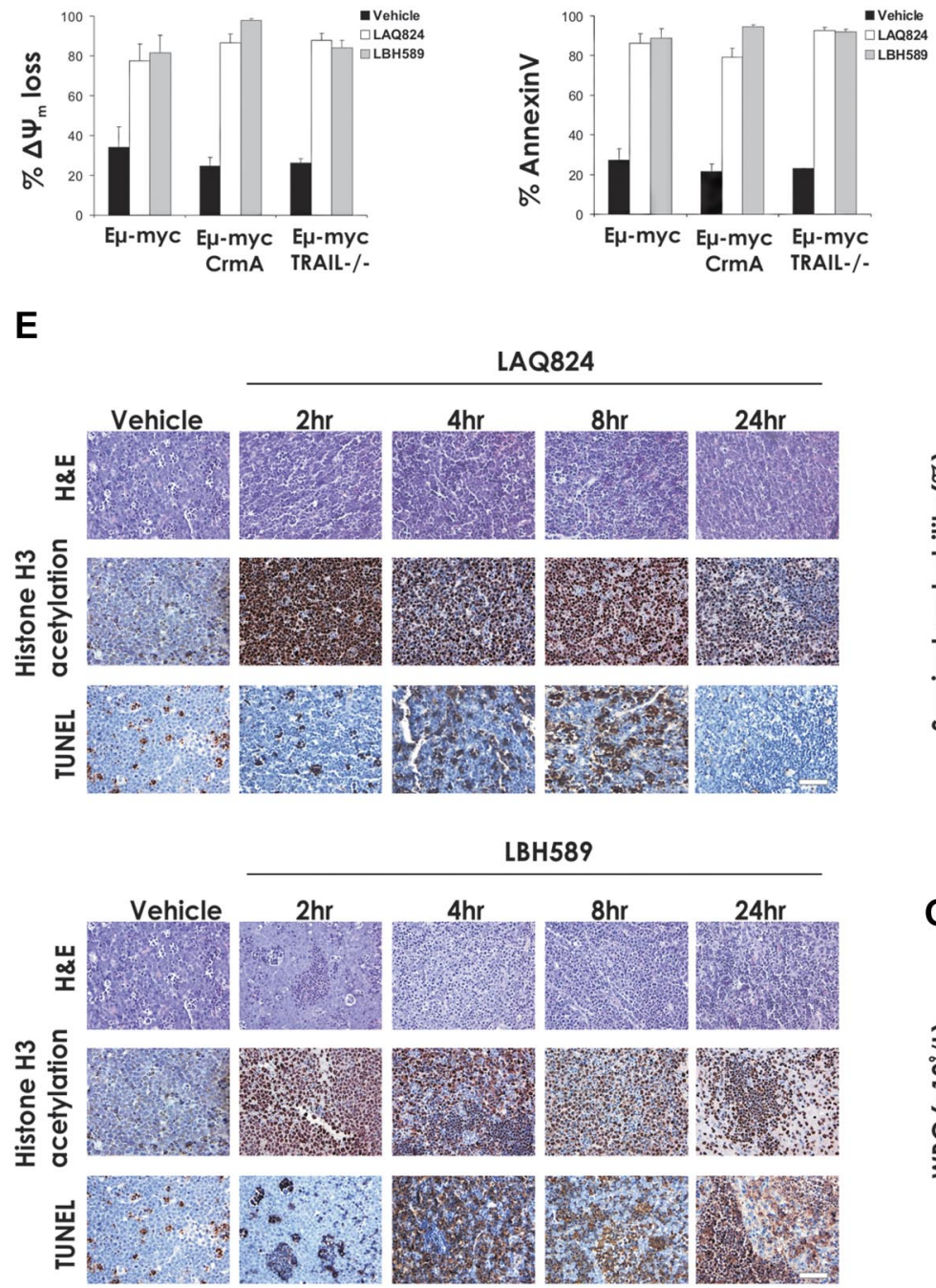

D

En-myc

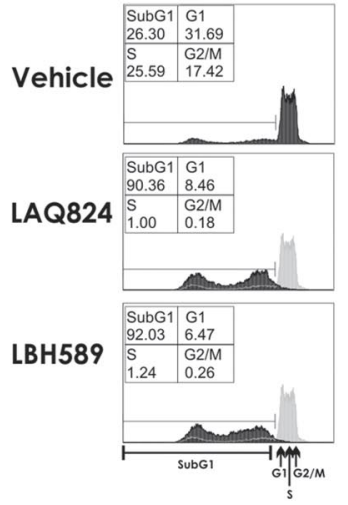

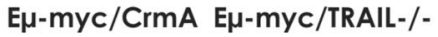
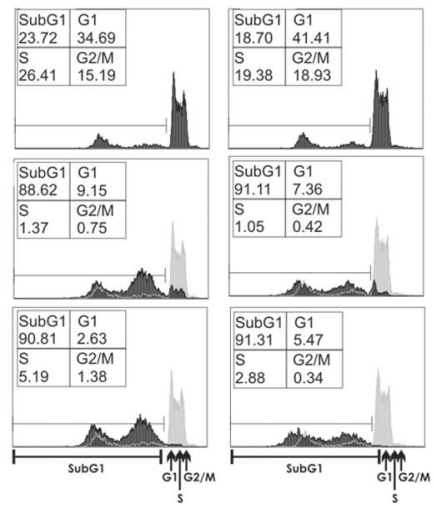

$\mathbf{F}$
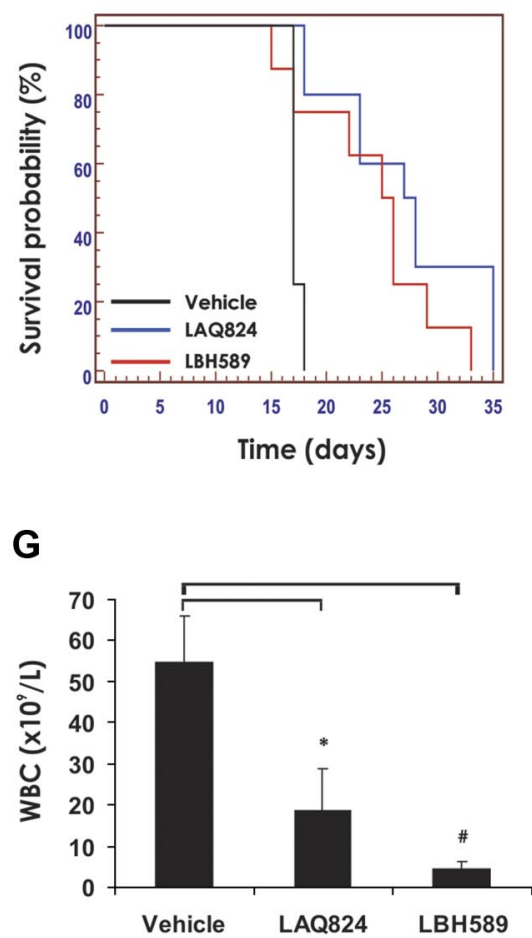

Figure 2. LAQ824- and LBH589-induced apoptosis and therapeutic efficacy do not require the death receptor pathway. (A) $\mathrm{E}_{\mu-m y c / C r m A}$ and $\mathrm{E}_{\mu-}-\mathrm{myc} / \mathrm{trail}^{-/}$ lymphoma cells were incubated for 24 hours with the indicated concentrations of LAQ824 or LBH589. Cell viability was determined by staining with PI and FACS analysis. (B) Whole cell lysates were prepared from $\mathrm{E}_{\mu}$-myc/CrmA lymphomas that had been treated for 2 hours with vehicle, LAQ824 (25 nM), or LBH589 (4 nM). Western blot analysis

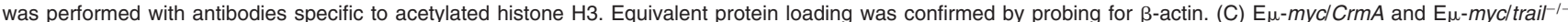
lymphomas were treated in vitro for 24 hours with vehicle ( $\square)$, LAQ824 (25 nM; $\square$ ), or LBH589 (4 nM; 圈). The extent of apoptosis was measured by flow cytometric analysis of the loss of $\Delta \psi \mathrm{m}$ and exposure of phosphatidylserine on the cell surface (annexin $\mathrm{V}$ staining). Each dose or time point represents the mean value of 3 individual experiments $\pm \mathrm{SE}$. (D) $\mathrm{E} \mu-m y c / C r m A$ and $\mathrm{E} \mu$-myc/trail/- lymphoma cells were treated in vitro for 24 hours with vehicle, LAQ824 (25 nM), or LBH589 (4 nM), and cell-cycle

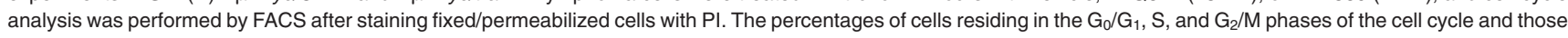
cells with less than $2 n$ DNA content (sub- $\mathrm{G}_{1}$ ) are indicated. Cells treated with vehicle are represented by the gray histograms in the middle and bottom panels. (E) $\mathrm{C} 57 \mathrm{BL} / 6$ mice bearing palpable $\mathrm{E} \mu-m y c / C r m A$ lymphomas were injected intravenously with LAQ824 (75 mg/kg) or LBH589 (80 mg/kg), and lymph nodes were harvested at the indicated 
additional independently derived $\mathrm{E} \mu-m y c$ lymphoma (E $\mu-m y c \# 2$; Table 1; supplemental Figure 1, available on the Blood website; see the Supplemental Materials link at the top of the online article).

\section{LAQ824 and LBH589 do not require TRAIL or the death receptor apoptotic pathway for killing of $\mathrm{E}_{\mu-m y c}$ lymphoma cells}

It has been reported that transcriptional induction of TRAIL and its cognate receptor DR5, resulting in enhanced cell surface expression of this death ligand/death receptor pair, is critical for HDACi-induced killing of primary acute myeloid leukemia (AML) cells. ${ }^{24,25}$ To assess the requirement of TRAIL and the importance of signaling through the death receptor pathway for apoptosis of E $\mu-m y c$ lymphoma cells induced by treatment with LAQ824 and LBH589, we generated E $\mu-m y c$ lymphomas lacking TRAIL (E $\mu$ mycltrail $\left.{ }^{-1-}\right)$ or overexpressing the viral serpin $\mathrm{CrmA}(\mathrm{E} \mu-m y c l$ CrmA; supplemental Figure 2). CrmA blocks death receptor signaling by inhibiting the enzymatic activity of caspase- $8 .{ }^{26}$ As shown in Figure 2A, E $\mu-m y c / C r m A$ and $\mathrm{E} \mu-m_{c} /$ trail $^{-1-}$ lymphomas were as sensitive to LAQ824- and LBH589-mediated apoptosis as control $\mathrm{E} \mu-m y c$ lymphomas, and both agents induced robust acetylation of histone $\mathrm{H} 3$ within 2 hours of incubation (Figure 2B). Loss of expression of TRAIL or overexpression of CrmA had no significant effect on the ability of these 2 HDACi to induce apoptosis, as measured by loss of mitochondrial membrane potential, surface exposure of phosphatidylserine as visualized by staining with annexin V (Figure 2C), or increased DNA fragmentation (Figure 2D).

To determine whether loss of death receptor signaling perturbed the therapeutic effects of LAQ824 or LBH589, C57BL/6 mice bearing an $\mathrm{E} \mu-m y c / C r m A$ lymphoma were treated with vehicle, LAQ824, or LBH589. Inhibition of death receptor signaling by CrmA had little or no effect on the ability of LAQ824 or LBH589 to induce histone hyperacetylation or TUNEL staining in vivo (Figure 2E). Consistent with these findings, mice bearing E $\mu-m y c /$ CrmA lymphomas showed enhanced survival (Figure 2F, median survival vehicle $=17$ days; median survival LAQ824 $=27.5$ days, $P=.001$; median survival LBH589 $=25.5$ days, $P=.05)$ and decreased WBC counts (Figure $2 \mathrm{G}$ ) after treatment with LAQ824 or LBH589. Similar results were obtained when using an independently derived E $\mu-m y c / C r m A$ lymphoma (E $\mu-m y c / C r m A \# 2$; Table 1; supplemental Figure 2). Taken together, these results indicate that death receptor signaling is dispensable for LAQ824and LBH589-induced apoptosis of E $\mu$-myc lymphoma cells in vitro or in vivo and for therapeutic efficacy in the treatment of these tumors in mice.

\section{Overexpression of prosurvival $\mathrm{Bcl}-2$ proteins suppresses the in vitro and in vivo apoptotic activities of LAQ824 and LBH589}

Given that death receptor signaling was not critical for HDACimediated killing of E $\mu-m y c$ lymphomas, it appeared probable that the Bcl-2-regulated intrinsic apoptotic pathway would be engaged. To examine this, we generated $\mathrm{E} \mu-m y c$ lymphomas overexpressing $\mathrm{Bcl}-2$ or $\mathrm{Bcl}-\mathrm{X}_{\mathrm{L}}$ by retroviral gene transduction of established $\mathrm{E} \mu-m y c$ lymphomas $\left(\mathrm{E} \mu-m y c / b c l-2\right.$ and $\mathrm{E} \mu-m y c / b c l-x_{L}$ lympho- mas; supplemental Figure 3) and examined their sensitivity to LAQ824 and LBH589 in vitro and in vivo. As shown in Figure 3A, lymphomas overexpressing $\mathrm{Bcl}-2$ or $\mathrm{Bcl}-\mathrm{X}_{\mathrm{L}}$ were completely resistant to LAQ824- and LBH589-induced apoptosis after 24-hour exposure to the compounds. Hyperacetylation of histone $\mathrm{H} 3$ still occurred in these cells in response to treatment with LAQ824 and LBH589 (Figure 3B), demonstrating that the compounds were active in these cells. To ensure that overexpression of $\mathrm{Bcl}-2$ or $\mathrm{Bcl}-\mathrm{X}_{\mathrm{L}}$ did not merely delay apoptosis mediated by LAQ824 or LBH589, E $\mu-m y c / b c l-2$ and $\mathrm{E} \mu-m y c / b c l-x_{L}$ lymphomas were treated with these agents continuously over 3 days. Lymphomas overexpressing $\mathrm{Bcl}-2$ or $\mathrm{Bcl}-\mathrm{X}_{\mathrm{L}}$ were able to survive extended exposure to LAQ824 or LBH589 (Figure 3C-D). Interestingly, although overexpression of Bcl-2 or Bcl- $\mathrm{X}_{\mathrm{L}}$ suppressed LAQ824and LBH589-induced apoptosis, both HDACi inhibited cell-cycle progression, evident by a decrease in cells in $\mathrm{S}$ phase and a concomitant increase of cells in the $G_{0} / G_{1}$ phases (Figure 3D) and induction of the cell-cycle inhibitor $\mathrm{p} 21^{\mathrm{WAF} 1 / \mathrm{CIP} 1}$ (supplemental Figure 4). This demonstrates that overexpression of Bcl-2 and Bcl- $\mathrm{X}_{\mathrm{L}}$ inhibits only the proapoptotic activity of HDACi but not other activities, such as induction of HDACi-responsive genes such as $c d k n l a$ and cell-cycle arrest. Similar results were obtained with lymphomas engineered to overexpress Bcl-w (data not shown).

Consistent with the in vitro data, overexpression of $\mathrm{Bcl}-2$ suppressed the apoptotic activities of LAQ824 and LBH589 in vivo (Figure 3E). Importantly, treatment with LAQ824 and LBH589 did not significantly extend the survival of mice bearing an $\mathrm{E} \mu-\mathrm{mycl}$ bcl-2 lymphoma (Figure 3F, median survival vehicle $=15$ days; median survival LAQ824 $=15$ days, $P=.12$; median survival LBH589 $=15$ days, $P=.47$ ), nor did these agents significantly decrease the WBC counts (Figure 3G). Similar in vivo data were obtained using an additional $\mathrm{E} \mu-m y c / \mathrm{Bcl}-2$ lymphoma $(\mathrm{E} \mu-m y c / b c l$ 2\#2; Table 1; supplemental Figure 3) and with E $\mu-m y c / b c l-x_{L}$ and $\mathrm{E} \mu-m y c / b c l-w$ lymphomas (data not shown). Collectively, these data demonstrate that activation of the intrinsic apoptotic pathway is necessary for LAQ824- and LBH589-induced killing of E $\mu-m y c$ lymphoma cells and the therapeutic efficacy of these drugs.

\section{Activity of LAQ824 and LBH589 in tumors devoid of a functional p53 pathway}

An intact p53 pathway is important for optimal activity of a number of chemotherapeutic drugs, ${ }^{27}$ and p53 has been proposed to play a role in the anticancer activities of HDACi. ${ }^{28}$ We therefore examined the HDACi sensitivity of E $\mu-m y c / p 53^{-1-}$ lymphomas and $\mathrm{E} \mu-$ myclarf $^{-1-}$ lymphomas, which retain wild-type $\mathrm{p} 53$ but have an attenuated oncogene-induced p53 response. ${ }^{23}$ LAQ824 and LBH589 induced apoptosis of $\mathrm{E} \mu-m y c / p 53^{-1-}$ and $\mathrm{E} \mu-\mathrm{myc}_{\mathrm{arf}}{ }^{-1-}$ lymphomas at a rate comparable with that observed with control E $\mu-m y c$ lymphomas (Figure 4A-D). Treatment of C57BL/6 mice bearing an $\mathrm{E} \mu-m y c / p 53^{-1-}$ lymphoma with LAQ824 or LBH589 resulted in rapid histone hyperacetylation and TUNEL staining (Figure 4E), a reduction in the WBC count (Figure 4G), and a concomitant increase in mouse survival (Figure $4 \mathrm{~F}$, median survival vehicle $=20$ days; median survival LAQ824 $=26$ days, $P \leq .001$; median survival LBH589 $=33$ days, $P \leq .001)$. Similar results

times. Histologic sections were assessed by hematoxylin and eosin staining (top panel), immunohistochemistry using antibodies to acetyl histone $\mathrm{H} 3$ (middle panel), and TUNEL staining (bottom panel). Each time point is of an individual mouse. (F) C57BL/6 mice bearing an E $\mu$ - $m y c / C r m A$ lymphoma were injected with vehicle (200 $\mu \mathrm{L} 10 \%$ lactic acid/D5W; $n=10)$, LAQ824 (75 mg/kg; $n=10)$, or LBH589 (80 mg/kg; $n=10)$. Kaplan-Meier survival curves of mice treated with vehicle (black line), LAQ824 (blue line), or LBH589 (red line) are shown. (G) WBC counts of mice bearing an $\mathrm{E} \mu-m y c / C r m A$ lymphoma $(\mathrm{n}=3)$ were taken 3 days after treatment with vehicle, LAQ824, or LBH589. Each point represents the mean value of 3 individual mice $\pm \mathrm{SE}\left({ }^{*} P=.03 ; \# P=.02\right)$. 
From bloodjournal.hematologylibrary.org at AUSTRALIAN NATL UNIV on February 18, 2013. For personal use

A
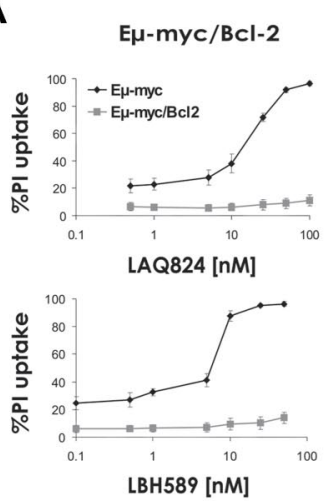

C
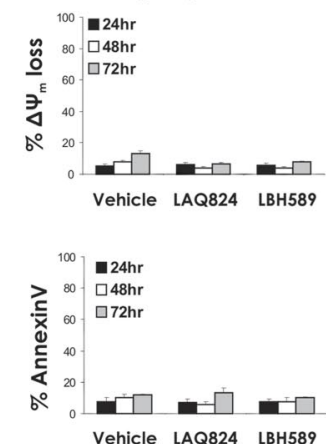

B
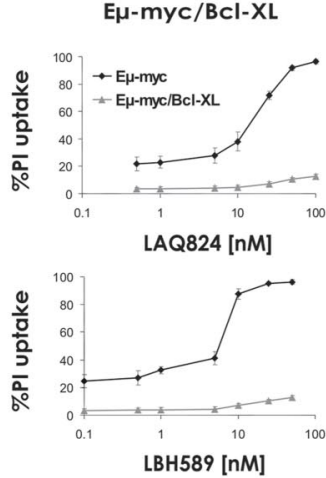

E $\mu-m y c / B c l-X L$
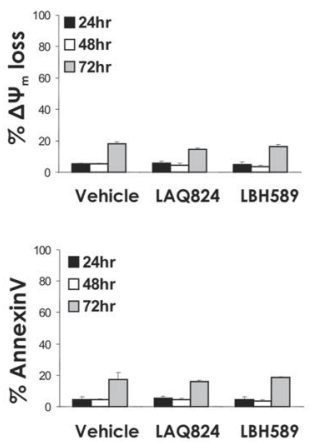

D

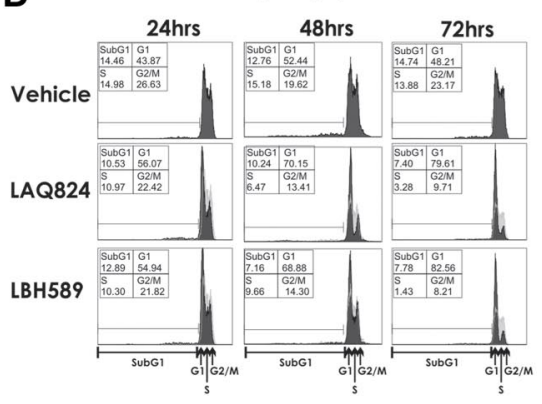

$\mathbf{E}$
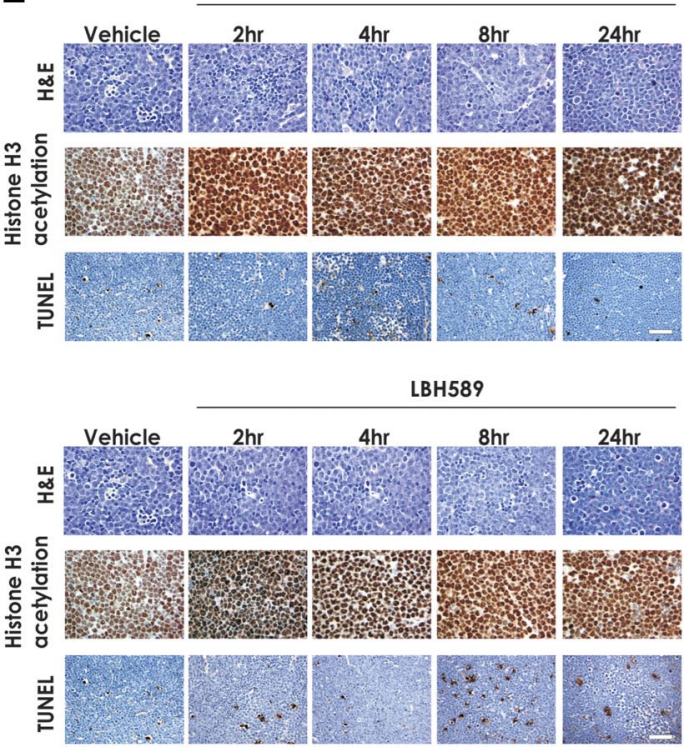

EM-myc/Bcl-XL

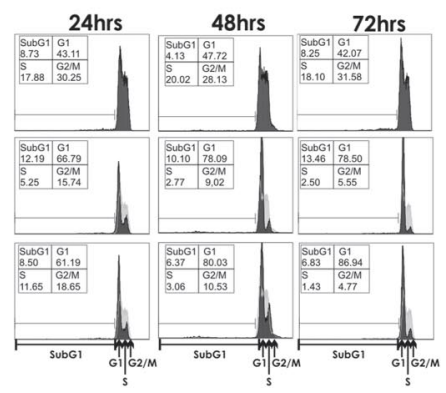

F

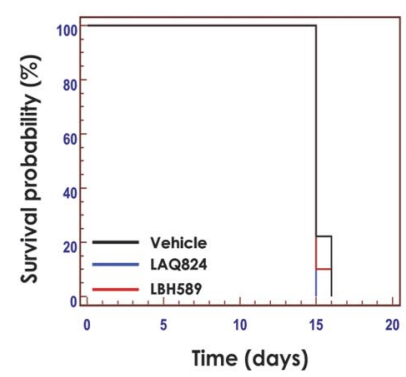

G

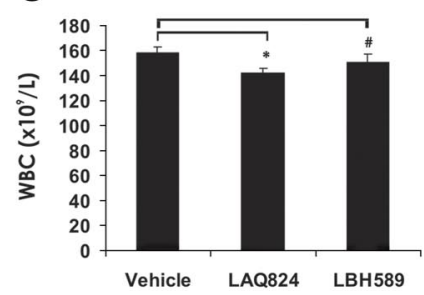


were observed in an independently derived $\mathrm{E} \mu-m y c / p 53^{-/-}$lym-

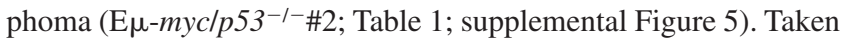
together, these data demonstrate that a functional p53 pathway is not required for the apoptosis-inducing or therapeutic activities of LAQ824 or LBH589.

\section{LAQ824 and LBH589 retain therapeutic activity in the absence of apoptosome formation}

Because our data demonstrated that activation of the intrinsic apoptotic pathway was necessary for HDACi-induced killing of E $\mu$-myc lymphomas and the consequent therapeutic activity of the compounds, we examined the requirements of the apoptosome components caspase- 9 and its activator Apaf- 1 for this process. This was assessed by measuring the sensitivity of E $\mu-m y c /$ apaf-1 $1^{-1-}$ and E $\mu$-myc/caspase- $9^{-1-}$ lymphomas to LAQ824 and LBH589. Deletion of Apaf-1 or caspase-9 reduced the extent of LAQ824- and LBH589-induced apoptosis of E $\mu$-myc lymphoma cells at 24 hours (Figure 5A), although the hyperacetylation of histone $\mathrm{H} 3$ mediated by these agents was unaffected (Figure $5 \mathrm{~B}$ ). Consistent with the data shown in Figure $5 \mathrm{~A}$, treatment with LAQ824 or LBH589 for 24 hours elicited little or no phosphatidylserine exposure, caspase activation, or DNA fragmentation (Figure 5C-D) in E $\mu$-myclapaf-1 $1^{-1-}$ and E $\mu$-myc/caspase-9 ${ }^{-1-}$ lymphomas compared with control E $\mu-m y c$ lymphomas. However, LAQ824 and LBH589 still caused a substantial decrease in TMRE staining, indicating that the mitochondrial outer membrane was being perturbed (Figure 5C). We additionally demonstrated perturbation of the mitochondrial membrane in E $\mu$-myclapaf-1 ${ }^{-1-}$ lymphomas treated with LBH589 and LAQ824 by assaying for release of cytochrome $\mathrm{c}$ from the mitochondria (supplemental Figure 6). A time course experiment revealed that, although LAQ824 and LBH589 induced maximal mitochondrial outer membrane permeabilization in an E $\mu$-myclapaf-1 ${ }^{-1-}$ lymphoma over time, there were only moderate or no increases in other apoptotic readouts, such as caspase activity, annexin $\mathrm{V}$ staining, and DNA fragmentation (Figure 5C-D). To determine the ultimate fate of E $\mu$-myclapaf-1 ${ }^{-1-}$ lymphomas after treatment with LAQ824 and LBH589, we performed clonogenic assays. As shown in Figure 5E, clonogenic survival of $\mathrm{E} \mu-m y c$ and $\mathrm{E} \mu-$ myclapaf-1 ${ }^{-1-}$ lymphomas was suppressed after treatment with LAQ824 and LBH589. In contrast, overexpression of Bcl-2, which also suppressed LAQ824and LBH589-induced apoptosis, caused a substantial increase in clonogenic survival (Figure 5E). These data demonstrate that, even in the absence of well-established hallmarks of apoptosis, such as caspase activation, exposure of phosphatidylserine on the cell surface, and DNA fragmentation, LAQ824 and LBH589 can cause loss of mitochondrial membrane potential and loss of clonogenic survival.
The activities of LAQ824 and LBH589 against an E $\mu-m y c /$ apaf-1 $1^{-1-}$ lymphoma within whole animals are documented in Figure $5 \mathrm{~F}$ through $\mathrm{H}$. Consistent with the finding that caspase activity and DNA fragmentation were suppressed in $\mathrm{E} \mu-\mathrm{mycl}$ apaf-1 $1^{-1-}$ lymphoma cells treated with LAQ824 or LBH589 in vitro, treatment with LAQ824 or LBH589 failed to cause an appreciable increase in TUNEL staining in E $\mu$-myclapaf-1 $1^{-1-}$ lymphoma-burdened mice. The drugs were, however, clearly active in these experiments, as evidenced by the hyperacetylation of histone H3 (Figure 5F). Remarkably, although they failed to induce many of the biochemical and morphologic hallmarks of apoptosis, both HDACi significantly enhanced the survival of mice bearing an E $\mu$-myclapaf-1 $1^{-1-}$ lymphoma (Figure 5G, median survival vehicle $=24$ days, median survival LAQ824 $=40$ days; $P \leq .001$, median survival LBH589 $=41$ days; $P \leq .001$ ) and decreased WBC counts below the pathologic threshold (Figure 5H). Similar results were observed in an independently derived $\mathrm{E} \mu-\mathrm{mycl}$ apaf-1 $1^{-1-}$ lymphoma (E $\mu$-myclapaf-1 $1^{-1-} \# 2$; Table 1; supplemental Figure 7). These results indicate that caspase activation downstream of mitochondrial perturbation and apoptosome formation are not essential for LAQ824 and LBH589 to kill E $\mu-m y c$ lymphomas and mediate a therapeutic response.

\section{LAQ824 and LBH589 induce morphologic changes associated with autophagy}

Our data indicate that $\mathrm{E} \mu-m y c$ lymphomas with an inactive apoptosome through knockout of apaf-1 or caspase-9 lose viability in response to treatment with LBH589 or LAQ824 in vitro and in vivo without displaying classic morphologic and biochemical features of apoptosis. It has recently been demonstrated that a range of anticancer agents, including HDACi, may induce death of tumor cells that have disrupted apoptotic machinery and that this can be associated with hallmarks of autophagy. ${ }^{29,30}$ Biochemical and morphologic features of autophagy include intracellular vacuolation and the formation of double-membrane autophagosomes that correlates with an increase in LC3-II that can be detected by Western blotting. ${ }^{29,31}$ We therefore treated $\mathrm{E} \mu-m y c$ and $\mathrm{E} \mu-m y c /$ apaf-1 $1^{-1-}$ lymphomas with LBH589 and LAQ824 in vitro and examined the cells for morphologic changes consistent with autophagy using TEM and Western blot analysis. As shown in Figure 6A, treatment of E $\mu$-myc lymphomas with HDACi resulted in cell shrinkage and chromatin condensation, typical features of apoptosis. In contrast, E $\mu$-myclapaf-1 $1^{-1-}$ lymphomas treated with LBH589 and LAQ824 did not shrink to the same extent, showed little or no chromatin condensation, but contained vacuoles and numerous double-membrane vesicles (Figure 6B). Western blot analysis showed that exposure of E $\mu-m y c l a p a f-1^{-1-}$ lymphoma

Figure 3. Overexpression of Bcl-2 suppresses LAQ824- and LBH589-mediated apoptosis and therapeutic efficacy. (A) $E_{\mu}-m y c$, $E_{\mu-} m y c / b c l-2$, and $E_{\mu-} m y c / b c l-x_{L}$ lymphoma cells were incubated for 24 hours with the indicated concentrations of LAQ824 or LBH589. Cell viability was determined by staining with PI and FACS analysis. (B) Whole cell lysates were prepared from $\mathrm{E}_{\mu}-m y c / b c l-2$ and $\mathrm{E}_{\mu}-m y c / b c /-x_{L}$ lymphoma cells that had been treated for 2 hours with vehicle, LAQ824 (25 nM), or LBH589 (4 nM). Western blot analysis was performed with antibodies specific for acetylated histone H3. Equivalent protein loading was confirmed by probing for $\beta$-actin. (C) $\mathrm{E} \mu$ - $m y c / b c l-2$ and $\mathrm{E}_{\mu}-\mathrm{myc} / \mathrm{bcl}$ - $x_{\mathrm{L}}$ lymphoma cells were treated with vehicle, LAQ824 (25 nM), or LBH589 (4 nM) for 24, 48, or 72 hours. The extent of apoptosis was measured by flow cytometric analysis of $\Delta \psi \mathrm{m}$ and exposure of phosphatidylserine on the cell surface (annexin $V$ staining). Each dose or time point represents the mean value of 3 individual experiments

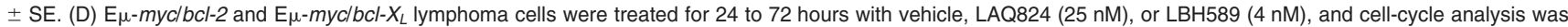

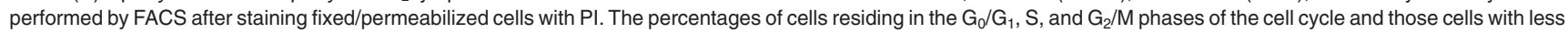
than 2n DNA content (sub- $\mathrm{G}_{1}$ ) are indicated. Cells treated with vehicle are represented by the gray histograms in the middle and bottom panels. (E) $\mathrm{C} 57 \mathrm{BL} / 6$ mice bearing palpable $\mathrm{E}_{\mu}-\mathrm{myc} / \mathrm{bcl}-2$ lymphomas were injected intravenously with LAQ824 $(75 \mathrm{mg} / \mathrm{kg})$ or LBH589 $(80 \mathrm{mg} / \mathrm{kg})$, and lymph nodes were harvested at the indicated times. Histologic sections were assessed by hematoxylin and eosin staining (top panel), immunohistochemistry using antibodies to acetyl histone $\mathrm{H} 3$ (middle panel), and TUNEL staining (bottom panel). Each time point is of an individual mouse. (F) C57BL/6 mice bearing an $\mathrm{E} \mu-m y c / b c l-2$ lymphoma were treated with vehicle (200 $\mu \mathrm{L} 10 \%$ lactic acid/D5W; $n=10)$, LAQ824 (75 mg/kg; $n=10)$, or LBH589 (80 mg/kg; $n=10)$. Kaplan-Meier survival curves of mice treated with vehicle (black line), LAQ824 (blue line), or LBH589 (red line) are shown. (G) WBC counts of mice bearing an $\mathrm{E}_{\mu}$-myc/bcl-2 lymphoma $(\mathrm{n}=3)$ were taken 3 days after treatment with vehicle, LAQ824, or LBH589I. Each point represents the mean value of 3 individual mice $\pm \operatorname{SE}\left({ }^{*} P=.1 ; \# P=.3\right)$. 
A
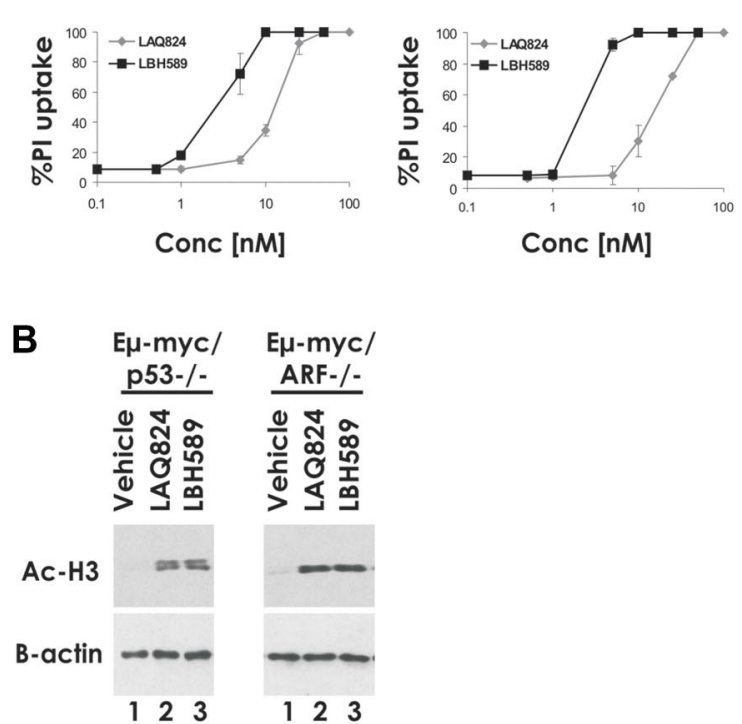

E

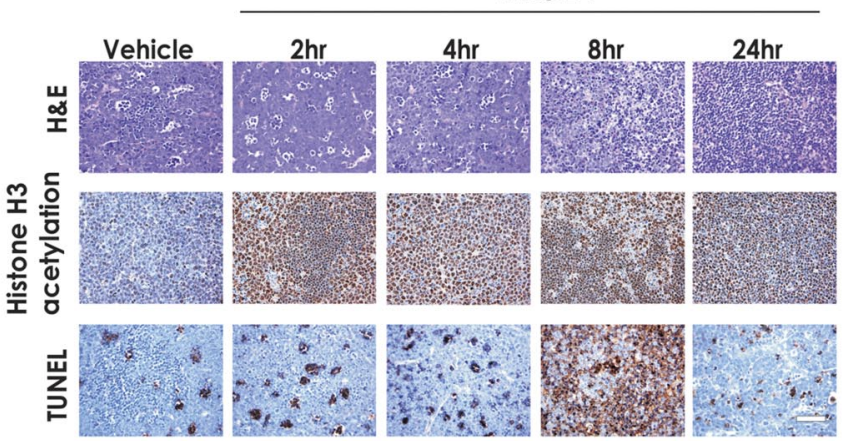

LBH589

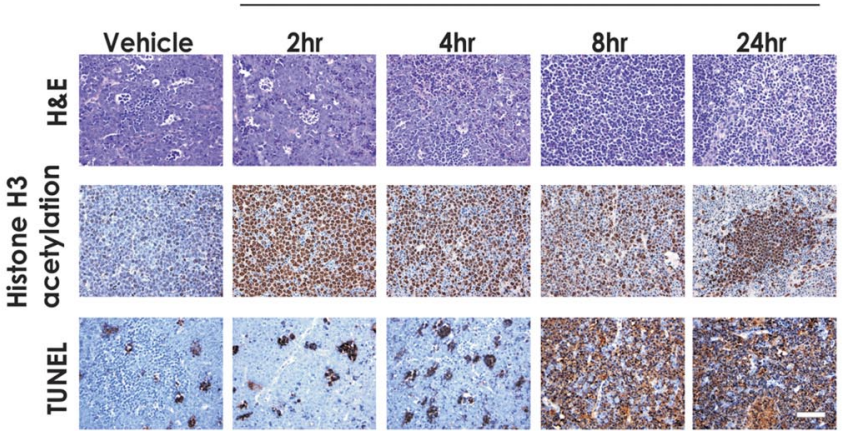

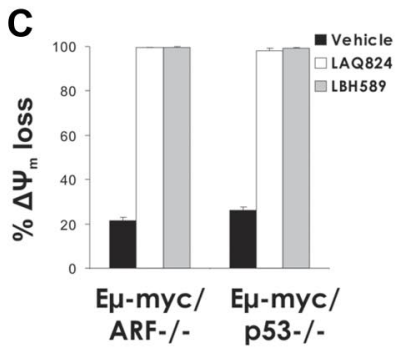

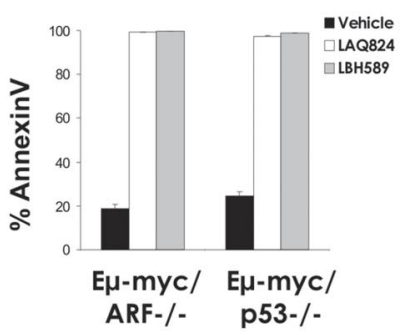

D

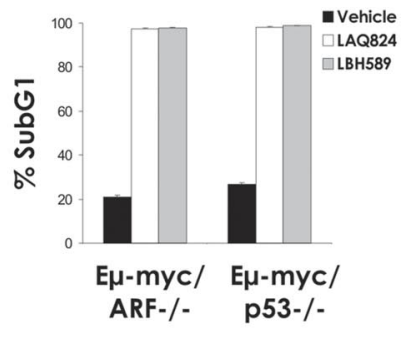

$\mathbf{F}$
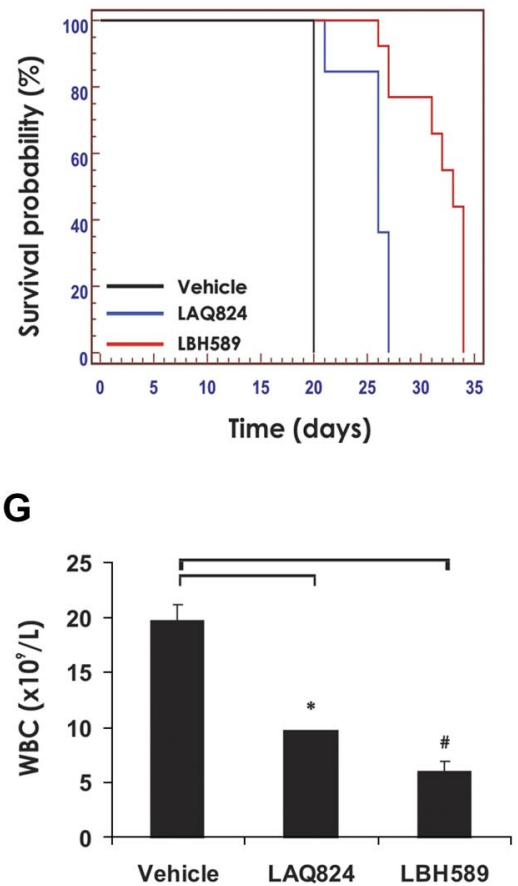

Figure 4. LAQ824- and LBH589-mediated apoptosis and therapeutic efficacy are independent of the p53 pathway. (A) $E \mu-m y c / p 53^{-/-}$and $E_{\mu-m y c / a r f} /-$ lymphoma cells were incubated for 24 hours with the indicated concentrations of LAQ824 or LBH589. Cell viability was determined by staining with PI and FACS analysis. (B) Whole cell lysates were prepared from $\mathrm{E} \mu-m y c / p 53^{-1-}$ and $\mathrm{E} \mu-m y c / a r f^{-1-}$ lymphomas that had been treated for 2 hours with vehicle, LAQ824 (25 nM), or LBH589 (4 nM). Western blot

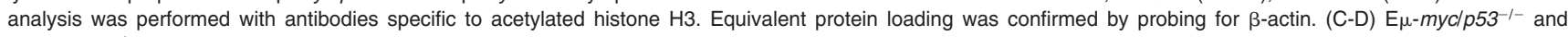
$\mathrm{E} \mu$-myc/arf ${ }^{-1}$ lymphomas were treated for 24 hours with vehicle ( $\square$ ), LAQ824 (25 nM; $\square$ ), or LBH589 (4 nM; 娄). The extent of apoptosis was measured by flow cytometric analysis of $\Delta \psi \mathrm{m}$, exposure of phosphatidylserine on the cell surface (annexin V staining), and presence of cells with less than $2 \mathrm{n}$ DNA content (PI staining of fixed/permeabilized cells). Each dose or time point represents the mean value of 3 individual experiments $\pm \mathrm{SE}$. (E) C57BL/6 mice bearing palpable $\mathrm{E} \mu-\mathrm{myc} / \mathrm{p} 53^{-1-}$ lymphomas were treated intravenously with LAQ824 $(75 \mathrm{mg} / \mathrm{kg})$ or LBH589 (80 mg/kg), and lymph nodes were harvested at the indicated times. Histologic sections were assessed by hematoxylin and eosin staining (top panel), immunohistochemistry using antibodies to acetyl histone $\mathrm{H} 3$ (middle panel), and TUNEL staining (bottom panel). Each time point is of an individual mouse. (F) C57BL/6 mice bearing an $\mathrm{E} \mu-m y c / p 53^{-1-}$ lymphoma were treated with vehicle (200 $\mu \mathrm{L} 10 \%$ lactic acid/D5W; $\mathrm{n}=10$ ), LAQ824 (75 mg/kg; $n=10)$, or LBH589 (80 mg/kg; $n=10)$. Kaplan-Meier survival curves of mice treated with vehicle (black line), LAQ824 (blue line), and LBH589 (red line) are shown. (G) WBC counts of mice bearing an $\mathrm{E} \mu-m y c / p 53^{-1-}$ lymphoma $(\mathrm{n}=3)$ were taken 3 days after treatment with vehicle, LAQ824, or LBH589. Each point represents the mean value of 3 individual mice $\pm \mathrm{SE}\left({ }^{*} P=.06, \# P=.002\right)$.

cells to LBH589 and LAQ824 caused an increase in the levels of LC3-II and a concomitant decrease in the amount of LC3-I (Figure 6C). Importantly, E $\mu-m y c / b c l-2$ and $\mathrm{E} \mu-m y c / b c l-X_{L}$ lymphomas treated with LAQ824 or LBH589 showed little change in the ratio of LC3-I to LC3-II (Figure 6C). These biochemical and morphologic changes are consistent with $\mathrm{E} \mu-m y c / a p a f-1^{-1-}$ lymphoma 
cells undergoing autophagy after treatment with LAQ824 or LBH589. Although this autophagy correlates with a loss of clonogenicity of the cells in vitro and therapeutic efficacy in vivo, at present it is not clear whether autophagy kills these cells or is activated as an emergency prosurvival response.

\section{Discussion}

HDACi are promising new chemotherapeutic compounds with pleiotropic molecular and biologic effects. ${ }^{3}$ LBH589 and LAQ824 are hydroxamic acid-type HDACi that have both entered clinical trials. ${ }^{5}$ In phase 1 clinical trials, LBH589 was well tolerated when administered either intravenously ${ }^{32}$ or orally. ${ }^{6}$ Moreover, we demonstrated that treatment of patients with cutaneous T-cell lymphoma with LBH589 resulted in a $60 \%$ partial or complete response rate. ${ }^{6}$ These agents are capable of mediating a variety of antitumor effects, such as induction of apoptosis, 7,11 cell-cycle arrest, ${ }^{12,13}$ and inhibition of angiogenesis. ${ }^{14,15}$ Although LBH589 and LAQ824 have proven therapeutic effects in preclinical models ${ }^{7,8,12,14,15}$ and in human patients, ${ }^{3,5,6}$ it is not clear which of their biologic action(s) account(s) for their antitumor efficacy in vivo.

Herein we have used the $\mathrm{E} \mu-m y c$ transgenic mouse model of pre-B/B-cell lymphoma to assess the link between induction of tumor cell death by the LBH589 and LAQ824 in vitro and in vivo and therapeutic efficacy. This tractable transgenic mouse model enabled us to identify the apoptotic pathways that were required for LBH589 and LAQ824 to kill E $\mu-m y c$ lymphoma cells. Consistent with previous reports showing that treatment of human tumorderived cell lines with LBH589 ${ }^{13}$ or LAQ824 ${ }^{18}$ resulted in mitochondrial membrane perturbation, cytochrome c release, and activation of caspase-9, we showed that these agents selectively activated the intrinsic apoptotic pathway (but not the death receptor pathway) to kill E $\mu$-myc lymphomas in vitro and in vivo. Importantly, we demonstrated that inhibition of the intrinsic apoptotic pathway, including blockade of mitochondrial membrane permeabilization, through overexpression of Bcl-2 or Bcl- $\mathrm{X}_{\mathrm{L}}$ abrogated the ability of LBH589 and LAQ824 to kill E $\mu$-myc lymphoma cells and rendered these agents ineffective in vivo even though they still induced expression of the cell-cycle inhibitor $\mathrm{p} 21^{\mathrm{WAF} 1 / \mathrm{CIP} 1}$ and a transient cell-cycle arrest at the $\mathrm{G}_{1} / \mathrm{S}$ boundary. Our studies therefore show a clear link between induction of the intrinsic apoptotic pathway by LBH589 and LAQ824 and therapeutic efficacy that supports our previous studies using vorinostat. ${ }^{21}$

It has previously been reported that the HDACi VPA, TSA, and MS-275 engage the death receptor pathway, particularly that mediated by the interaction of TRAIL with its cognate deathinducing receptors DR4 and/or DR5, to kill human and mouse AML cells. ${ }^{24,25}$ However, consistent with previous studies by us and others using a variety of primary tumor-derived cells and cell lines and structurally diverse HDACi, ${ }^{21,33-36}$ LAQ824 and LBH589 did not require activation of the death receptor pathway to trigger apoptosis of E $\mu-m y c$ lymphoma cells in vitro or in vivo. Moreover, inhibition of death receptor-mediated apoptosis through overexpression of the viral serpin CrmA, which inhibits the enzymatic activity of the death receptor pathway-associated caspase- 8 and caspase$10,{ }^{37}$ had no significant effect on the therapeutic efficacy of LBH589 or LAQ824. Whether use of the death receptor pathway by HDACi is specific to AML cells remains to be determined.

Having established that perturbation of mitochondrial membrane potential and activation of the intrinsic apoptotic pathway correlated with the therapeutic effects of LBH589 and LAQ824, we initiated studies to identify key molecules upstream and downstream of the mitochondria that were required for HDACi-induced killing of $\mathrm{E} \mu-m y c$ lymphomas. Chemotherapeutic drugs commonly engage the $\mathrm{p} 53$ pathway to activate the intrinsic apoptotic pathway. ${ }^{27}$ HDACi have been reported to mediate p53-dependent apoptosis ${ }^{28}$, and indeed, LBH589 has been shown to up-regulate p53. ${ }^{13}$ Conversely, our previous studies in the E $\mu$-myc lymphoma system with the HDACi, vorinostat revealed that p53 was not required for drug efficacy either in vitro or in vivo. ${ }^{20}$ Using E $\mu-m y c$ lymphomas deficient for $\mathrm{p} 53$ or its activator p19ARF, we demonstrated that a functional p53 pathway was not necessary for the apoptosis-inducing and therapeutic effects of LBH589 and LAQ824.

Loss of apoptosome (consisting of Apaf-1, caspase-9, and cytochrome c) function has been proposed to play a role in tumorigenesis and/or chemoresistance. ${ }^{38}$ This is based on findings indicating that $A P A F-1$ is silenced or inactivated in various hematologic and solid tumors, which often correlates with hypermethylation of the APAF-1 promoter $^{38,39}$ (and references therein). Moreover, melanoma cells with loss of Apaf-1 expression resulting from promoter methylation demonstrated chemoresistance that could be reversed after restoration of Apaf- 1 expression. ${ }^{40}$ However, the importance of a functional apoptosome in tumor onset and sensitivity to anticancer drugs may be context dependent. Some studies support the notion that loss of apoptosome function may suppress the activity of chemotherapeutic drugs. ${ }^{41-43}$ However, loss of Apaf-1 or caspase-9 had no effect on E $\mu$-myc-induced lymphoma development and E $\mu$-myclapaf- $1^{-1-}$ cells remained sensitive to dexamethasone and etoposide, although a delay in the kinetics of drug-induced apoptosis was observed. ${ }^{22}$ Moreover, normal levels of Apaf-1 expression were found in melanoma samples and cell lines in 2 later studies. ${ }^{44,45}$

We tested whether activation of the apoptosome downstream of mitochondrial membrane perturbation was essential for the deathinducing and therapeutic activities of LAQ824 and LBH589. Although common hallmarks of apoptosis, such as annexin V staining, caspase activation, and DNA fragmentation, were severely attenuated or even abrogated in $\mathrm{E} \mu$-myc lymphomas lacking Apaf-1 or caspase-9 after treatment with LAQ824 or LBH589, mitochondrial membrane potential and clonogenic capacity were still lost. These results were similar to those reported using IL-3-dependent immortalized promyelocytic cell lines derived from apaf-1 or caspase-9 knockout mice that lost clonogenic potential after withdrawal of IL-3 in the absence of plasma membrane permeabilization or phosphatidylserine exposure. ${ }^{46} \mathrm{Simi}-$ larly, mast cells with knockout of apaf-1 or caspase-9 lost their clonogenic potential after cytokine withdrawal without disruption of plasma membrane integrity or exposure of phosphatidylserine. ${ }^{47}$ In contrast, primary mouse $\mathrm{T}$ lymphocytes lacking Apaf-1 or caspase-9 displayed characteristics of apoptosis, including phosphatidylserine exposure and DNA fragmentation after treatment with $\gamma$-irradiation or cytokine withdrawal. ${ }^{48}$ These contrasting results might reflect differences in cell type or the effects of Myc-induced transformation. Importantly, we found that $\mathrm{E} \mu$-myclapaf $-1^{-1-}$ and E $\mu$-myc/caspase $-9^{-1-}$ lymphomas were normally responsive to the therapeutic effects of LAQ824 or LBH589 in vivo, demonstrating that late events in apoptosis signaling (downstream of outer mitochondrial membrane permeabilization) are not required for killing these lymphoma cells and therapeutic efficacy. Interestingly, E $\mu-m y c / a p a f-1^{-I-}$ lymphomas treated with LAQ824 or LBH589 displayed morphologic and biochemical features characteristic of autophagy, and similar changes were previously observed in vorinostat-treated Apaf-1-deficient mouse embryonic fibroblasts. ${ }^{30}$ 
From bloodjournal.hematologylibrary.org at AUSTRALIAN NATL UNIV on February 18, 2013. For personal use

A
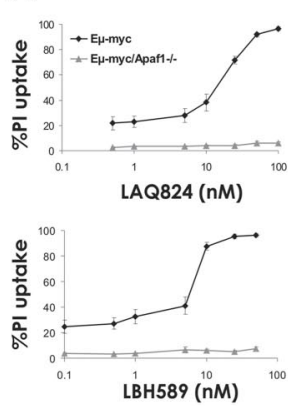
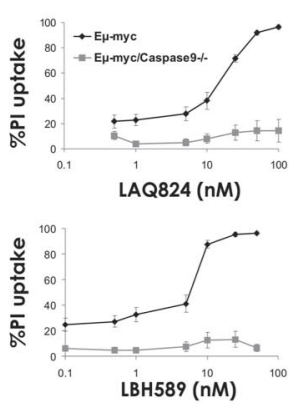

B

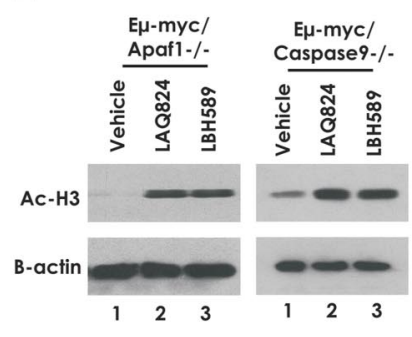

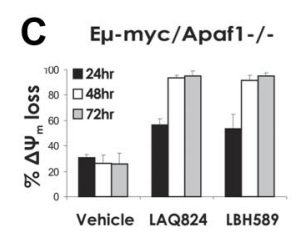

EH-myc/Caspase9-/-

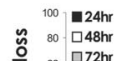

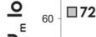

$\begin{array}{ll}\vartheta^{\varepsilon} & 40 \\ \text { 犬ீ } & 20\end{array}$

Vehicle LAQ824 LBH589

Vehicle LAQ824 LBH589
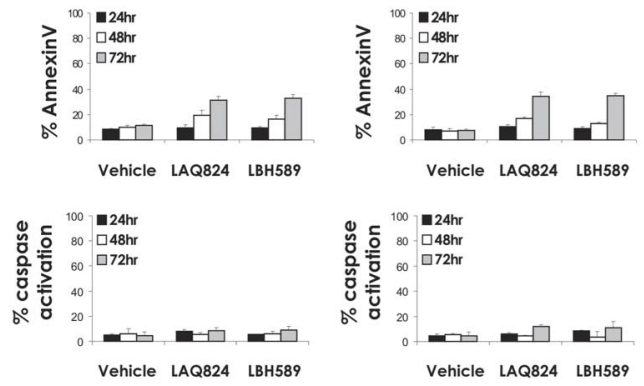

D Ej-myc/Apaf1-/En-myc/Caspase9-/-
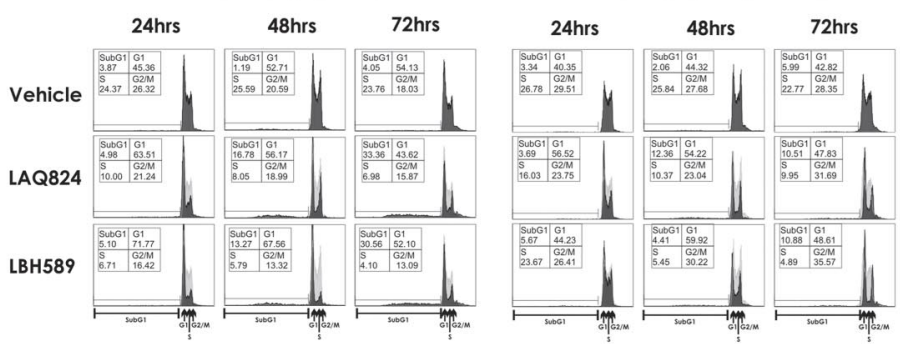

E

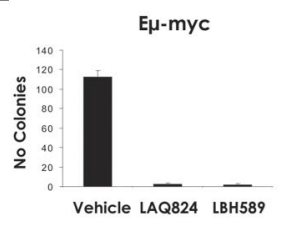

Ep-myc Apaf-1-/

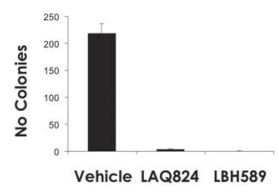

E $\mu-m y c ~ B c l 2$

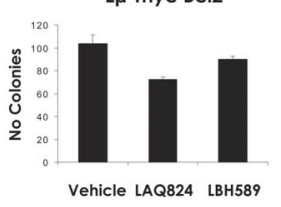

$\mathbf{F}$
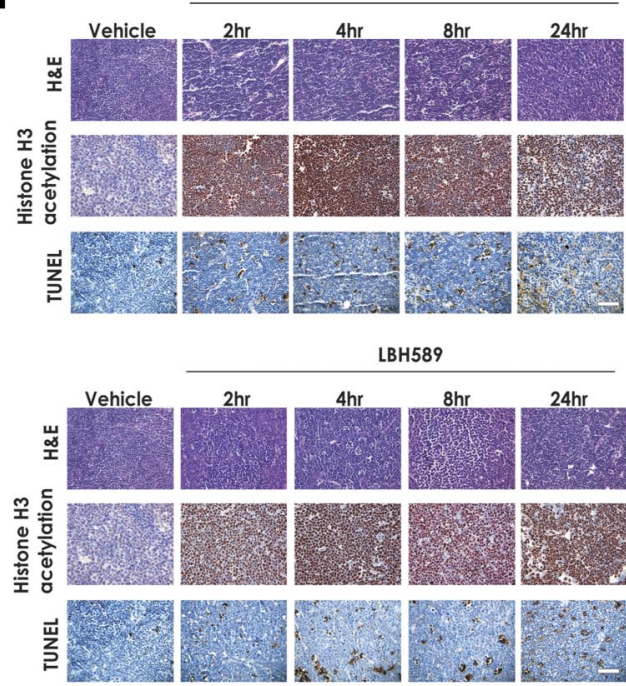

G

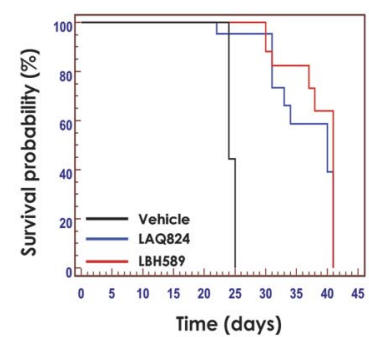

H

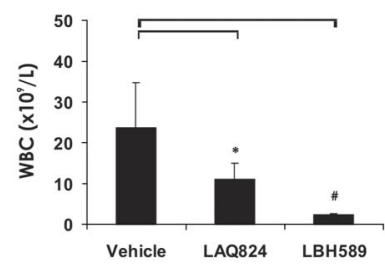


A

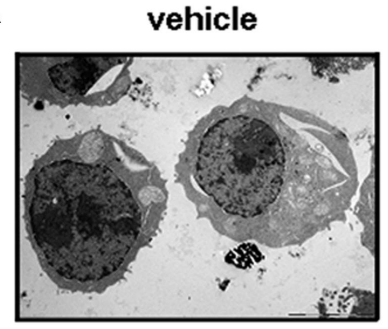

LAQ824

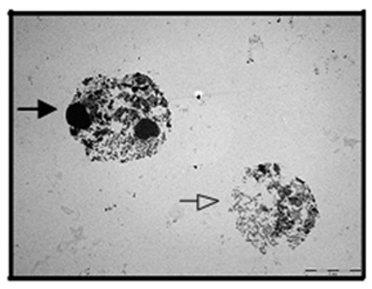

C

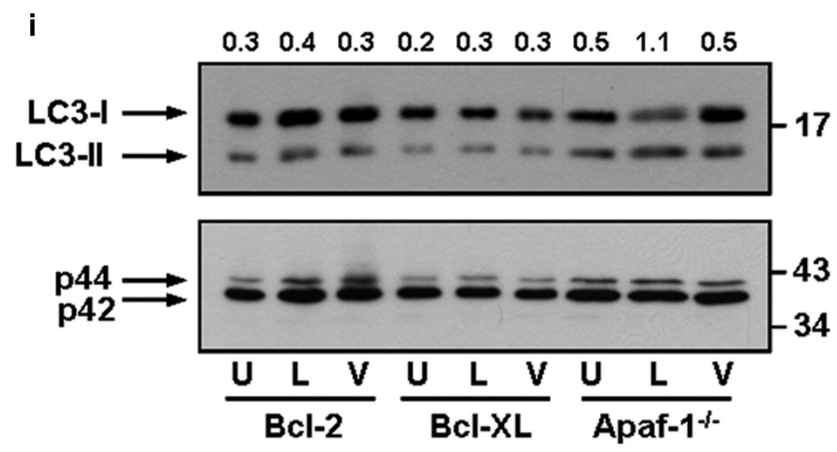

ii
B

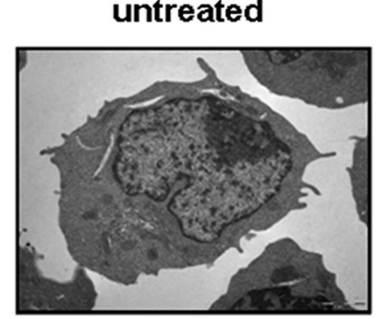

LBH589
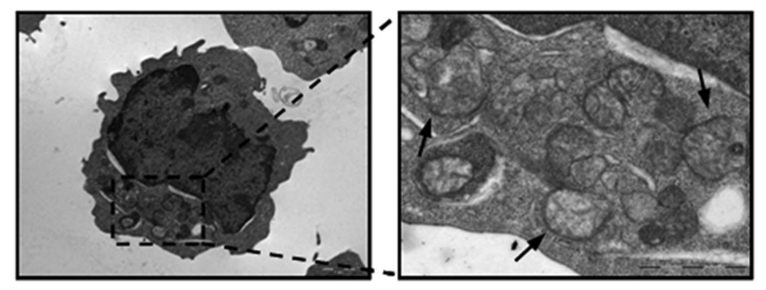

LAQ824

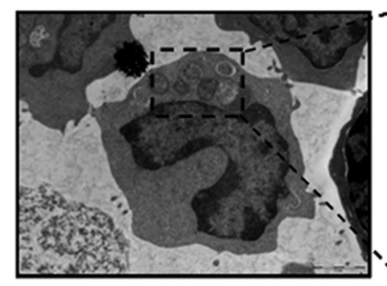

vehicle

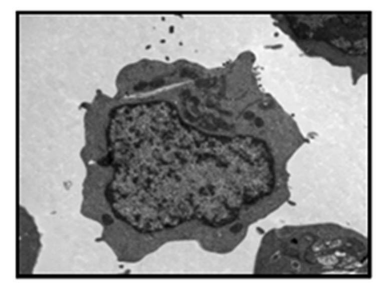

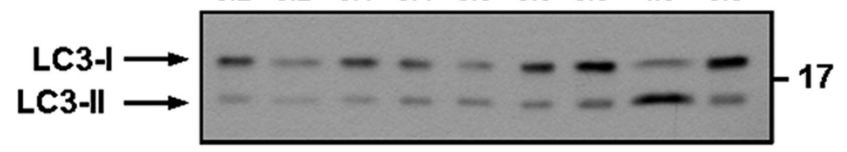

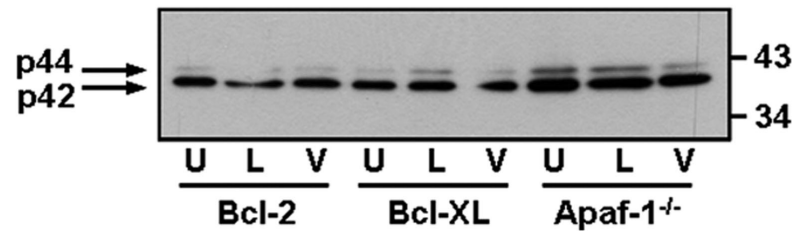

Figure 6. HDACi induce morphologic and biochemical changes associated with autophagy. (A) E $\mu$-myc lymphoma cells were treated for 24 hours with vehicle or LAQ824 $(25 \mathrm{nM})$ and assessed by TEM. $\rightarrow$ indicates an apoptotic shrunken cell with condensed nuclei; $\rightarrow$, a cell with a disrupted outer cell membrane. (B) E $\mu-m y c / a p a f-1^{-1-}$ lymphomas were left untreated or treated for 24 hours with vehicle, LAQ824 (25 nM), or LBH589 (4 nM) and assessed by TEM. Treatment of E $\mu$-myc/apaf-1-1- lymphoma cells with LAQ824 or LBH589 for 24 hours resulted in the formation of autophagic vacuoles. Higher magnification shows autophagic vacuoles

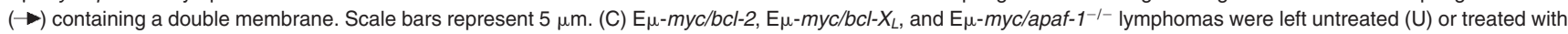
(i) 4 nM LBH589 (L) or vehicle (V) or (ii) 25 nM LAQ824 (L) or vehicle (V) for 24 hours and analyzed for endogenous LC3 by Western blot (top panels). $\rightarrow$ indicate positions of LC3-I and LC3-II. The ratio of LC3-II to LC3-I was assessed by densitometry and is displayed above each lane. Membranes were stripped and reprobed for p42 as loading control (bottom panels).

These findings raise the intriguing possibility that, in the absence of an intact intrinsic apoptotic cascade, HDACi can induce autophagy resulting in loss of tumor cell viability and ultimately therapeutic efficacy, but it is also possible that the autophagy that was observed represents a survival-promoting response of the tumor cells. ${ }^{49}$ Interestingly, treatment of tumor cells with chloroquine or 3-methyladenine that can inhibit autophagy can augment vorinostat-mediated caspase activation and apoptosis in cells that

Figure 5. LAQ824 and LBH589 do not require a functional apoptosome for the killing of $E_{\mu}-m y c$ lymphoma cells and therapeutic efficacy. (A) E $\mu$-myc, $\mathrm{E} \mu-\mathrm{myc}_{\text {apaf-1 }}{ }^{-1-}$, and $E \mu-\mathrm{myc} / \mathrm{caspase}-9^{-/-}$lymphoma cells were incubated for 24 hours with the indicated concentrations of LAQ824 or LBH589. Cell viability was determined by staining with PI and FACS analysis. (B) Whole cell lysates were prepared from E $\mu-m y c / a p a f-1^{-/-}$and E $\mu-m y c / c a s p a s e-9^{-/-}$lymphoma cells that had been treated for 2 hours with vehicle, LAQ824 (25 nM), or LBH589 (4 nM). Western blot analysis was performed with antibodies specific to acetylated histone H3. Equivalent protein loading was confirmed by probing for $\beta$-actin. (C) $\mathrm{E}_{\mu}$-myc/apaf-1 ${ }^{-1-}$ and $\mathrm{E}_{\mu}$-myc/caspase- $9^{-/-}$lymphoma cells were treated for 24 to 72 hours with vehicle, LAQ824 (25 nM), or LBH589 (4 nM). The extent of apoptosis was measured by flow cytometric analysis of $\Delta \psi \mathrm{m}$, exposure of phosphatidylserine on the cell surface (annexin $\mathrm{V}$ staining) and caspase activation. Each dose or time point represents the mean value of 3 individual experiments \pm SE. (D) E $\mu-m y c / a p a f-1^{-1-}$ and $E \mu-m y c / c a s p a s e-9^{-/-}$lymphoma cells were treated for 24 to 72 hours with vehicle, LAQ824 (25 nM), or LBH589 (4 nM), and cell-cycle analysis was performed by FACS after staining fixed/permeabilized cells with $\mathrm{PI}$. The percentages of cells residing in the $\mathrm{G}_{0} / \mathrm{G}_{1}, \mathrm{~S}$, and $\mathrm{G}_{2} / \mathrm{M}$ phases of the cell cycle and those cells with less than $2 N$ DNA content (sub- $\mathrm{G}_{1}$ ) are indicated. Cells treated with

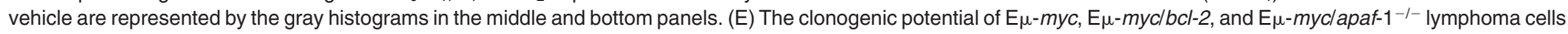
treated for 24 hours with vehicle, LAQ824, or LBH589 was assessed by plating treated cells in soft agar and counting colonies after 10 days in culture. Results shown represent the mean \pm SE of 3 separate experiments. (F) C57BL/6 mice bearing palpable E $\mu$-myc/apaf-1 ${ }^{-1-}$ lymphomas were treated intravenously with LAQ824 (75 mg/kg) or LBH58 $(80 \mathrm{mg} / \mathrm{kg})$, and lymph nodes were harvested at the indicated times. Histologic sections were assessed by hematoxylin and eosin staining (top panel), immunohistochemistry using antibodies to acetyl histone $\mathrm{H} 3$ (middle panel), and TUNEL staining (bottom panel). Each time point is of an individual mouse. (G) C57BL/6 mice bearing an E $\mu$-myclapaf-1 ${ }^{-1-}$ lymphoma were treated with vehicle $(200 \mu \mathrm{L} 10 \%$ lactic acid/D5W; $\mathrm{n}=10)$, LAQ824 (75 mg/kg; $\left.\mathrm{n}=10\right)$, or LBH589 (80 mg/kg; $\left.\mathrm{n}=10\right)$. Kaplan-Meier survival curves of mice treated with vehicle (black line), LAQ824 (blue line), or LBH589 (red line) are shown. (H) WBC counts of mice bearing an E $\mu-m y c / a p a f-1^{-/-}$lymphoma $(\mathrm{n}=3)$ were taken 3 days after treatment with vehicle, LAQ824, or LBH589. Each point represents the mean value of 3 individual mice \pm SE $\left({ }^{\star} P=.19 ; \# P=.09\right)$. 
have an intact intrinsic apoptotic pathway. ${ }^{50}$ In our system, chloroquine and 3-methyladenine were toxic to lymphoma cells, and we were therefore unable to determine whether these agents could enhance or suppress death of E $\mu$-myclapaf-1 ${ }^{-1-}$ or E $\mu-m y c /$ caspase $-9^{-1-}$ lymphomas after HDACi treatment. Future planned experiments using E $\mu$-myclapaf-1 ${ }^{-/-}$and E $\mu$-myclcaspase-9-1lymphomas with knockout or knockdown of key autophagy genes, such as ATG5, ATG6, and ATG7,51 should allow us to determine whether autophagy plays an active role in regulating HDACiinduced death of tumor cells that have defective apoptosis pathways because of the absence of a functional apoptosome. The clinical benefit of inducing autophagy in tumor cells has recently been proposed, ${ }^{29,52,53}$ and HDACi may therefore join a select group of agents, such tamoxifen, ${ }^{54}$ mTOR inhibitors (eg, rapamycin), ${ }^{55}$ and suppressors of Bcl-2 function (eg, ABT-737) ${ }^{56}$ that can induce autophagy, which could play a role in mediating clinical responses in cells with defective apoptosis mechanisms.

In conclusion, we have shown that the HDACi LAQ824 and LBH589 induce apoptosis of E $\mu-m y c$ lymphomas via the intrinsic apoptotic pathway with no evidence for a significant role of the death receptor pathway. Induction of lymphoma cell death in vitro and in vivo by LAQ824 and LBH589 directly correlated with the therapeutic efficacy of these HDAC inhibitors. Interestingly, inhibition of later stages of apoptosis signaling through functional inactivation of the apoptosome (through knockout of apaf-1 or caspase-9) suppressed many of the morphologic features of apoptosis but did not diminish the effects of LAQ824 and LBH589 on mitochondrial membrane permeabilization, clonogenic survival, or therapeutic efficacy. Cells deficient in apoptosome function and treated with LAQ824 or LBH589 displayed morphologic features of autophagy. Whether induction of autophagy is a mediator of lymphoma cell death after treatment with these agents or reflects a prosurvival response of these cells to loss of mitochondrial function as has been suggested ${ }^{57}$ remains to be determined.

\section{Acknowledgments}

The authors thank David Huang, Jerry Adams, Suzanne Cory, and Alan Harris from the Walter and Eliza Hall Institute for helpful advice, E $\mu-m y c$ mice, and cDNAs for bcl-2 and bcl- $\mathrm{x}_{\mathrm{L}}$ and bcl-w; members of the Johnstone laboratory and the Cancer Immunology and Cancer Therapeutics Programs for technical help and advice, and Sarah Ellis and members of the Peter MacCallum Cancer Centre microscopy core for technical help. LBH589 and LAQ824 were kindly provided by Novartis.

R.W.J. is a Pfizer Australia Research Fellow and was supported by the National Health and Medical Research Council of Australia (program grant 251608), the Cancer Council Victoria, the Leukemia Foundation of Australia, and the Bennelong Foundation. L.E. was supported by a postgraduate scholarship from the Leukemia Foundation of Australia. M.B. was supported by a Rubicon research grant from Netherlands Organisation for Scientific Research. A.S. was supported by the National Health and Medical Research Council of Australia (program grant 257502; Australia Fellowship) and the Leukemia \& Lymphoma Society (New York, NY; Specialized Center of Research grant 7015). C.L.S. was supported by National Health and Medical Research Council of Australia RD Wright Biomedical (CDA 406675).

\section{Authorship}

Contribution: L.E. performed research, analyzed data, and wrote the paper; M.B. performed research and analyzed data; R.K.L., J.E.B., and A.N. performed research; L.A.C. performed research and contributed vital new reagents; C.L.S. and A.S. contributed vital new reagents and assisted with writing of the manuscript; P.A. and S.W.L. contributed vital new reagents; and R.W.J. analyzed data and wrote the paper.

Conflict-of-interest disclosure: R.W.J. received a collaborative research grant from Novartis for research involving LAQ824 and LBH589. P.A. is a paid employee of Novartis. The remaining authors declare no competing financial interests.

Correspondence: Ricky W. Johnstone, Cancer Therapeutics Program, Gene Regulation Laboratory, Peter MacCallum Cancer Centre, Trescowthick Research Laboratories, St Andrews Pl, East Melbourne 3002 Victoria, Australia; e-mail: ricky.johnstone@ petermac.org.

\section{References}

1. Lund $A H$, van Lohuizen M. Epigenetics and cancer. Genes Dev. 2004;18:2315-2335.

2. Baylin SB, Ohm JE. Epigenetic gene silencing in cancer: a mechanism for early oncogenic pathway addiction? Nat Rev Cancer. 2006;6:107-116.

3. Bolden JE, Peart MJ, Johnstone RW. Anticancer activities of histone deacetylase inhibitors. Nat Rev Drug Discov. 2006;5:769-784.

4. Atadja P, Hsu M, Kwon P, Trogani N, Bhalla K, Remiszewski S. Molecular and cellular basis for the anti-proliferative effects of the HDAC inhibitor LAQ824. Novartis Found Symp. 2004;259:249266; discussion 266-248, 285-248.

5. Rasheed WK, Johnstone RW, Prince HM. Histone deacetylase inhibitors in cancer therapy. Expert Opin Investig Drugs. 2007;16:659-678.

6. Ellis L, Pan Y, Smyth GK, et al. Histone deacetylase inhibitor panobinostat induces clinical responses with associated alterations in gene expression profiles in cutaneous T-cell lymphoma. Clin Cancer Res. 2008;14:4500-4510.

7. Catley L, Weisberg E, Tai YT, et al. NVP-LAQ824 is a potent novel histone deacetylase inhibitor with significant activity against multiple myeloma. Blood. 2003;102:2615-2622.
8. Weisberg E, Catley L, Kujawa J, et al. Histone deacetylase inhibitor NVP-LAQ824 has significant activity against myeloid leukemia cells in vitro and in vivo. Leukemia. 2004;18:1951-1963.

9. Nimmanapalli R, Fuino L, Bali $P$, et al. Histone deacetylase inhibitor LAQ824 both lowers expression and promotes proteasomal degradation of Bcr-Abl and induces apoptosis of imatinib mesylate-sensitive or -refractory chronic myelogenous leukemia-blast crisis cells. Cancer Res. 2003;63:5126-5135.

10. Bali P, Pranpat M, Bradner J, et al. Inhibition of histone deacetylase 6 acetylates and disrupts the chaperone function of heat shock protein 90: a novel basis for antileukemia activity of histone deacetylase inhibitors. J Biol Chem. 2005;280: 26729-26734.

11. George P, Bali P, Annavarapu S, et al. Combination of the histone deacetylase inhibitor LBH589 and the hsp90 inhibitor 17-AAG is highly active against human $C M L-B C$ cells and $A M L$ cells with activating mutation of FLT-3. Blood. 2005;105: 1768-1776.

12. Atadja $P, G a o L$, Kwon $P$, et al. Selective growth inhibition of tumor cells by a novel histone deacetylase inhibitor, NVP-LAQ824. Cancer Res. 2004;64:689-695.

13. Maiso $P$, Carvajal-Vergara $X$, Ocio EM, et al. The histone deacetylase inhibitor LBH589 is a potent antimyeloma agent that overcomes drug resistance. Cancer Res. 2006;66:5781-5789.

14. Qian DZ, Kato Y, Shabbeer S, et al. Targeting tu mor angiogenesis with histone deacetylase inhibitors: the hydroxamic acid derivative LBH589. Clin Cancer Res. 2006;12:634-642.

15. Qian DZ, Wang X, Kachhap SK, et al. The histone deacetylase inhibitor NVP-LAQ824 inhibits angiogenesis and has a greater antitumor effect in combination with the vascular endothelial growth factor receptor tyrosine kinase inhibitor PTK787/ZK222584. Cancer Res. 2004;64:66266634.

16. Guo F, Sigua C, Tao J, et al. Cotreatment with histone deacetylase inhibitor LAQ824 enhances Apo-2L/tumor necrosis factor-related apoptosis inducing ligand-induced death inducing signaling complex activity and apoptosis of human acute leukemia cells. Cancer Res. 2004;64:2580-2589.

17. Rosato RR, Maggio SC, Almenara JA, et al. The histone deacetylase inhibitor LAQ824 induces human leukemia cell death through a process 
involving XIAP down-regulation, oxidative injury, and the acid sphingomyelinase-dependent generation of ceramide. Mol Pharmacol. 2006;69: 216-225.

18. Wang S, Yan-Neale Y, Cai R, Alimov I, Cohen D. Activation of mitochondrial pathway is crucial for tumor selective induction of apoptosis by LAQ824. Cell Cycle. 2006;5:1662-1668.

19. Adams JM, Harris AW, Pinkert CA, et al. The Cmyc oncogene driven by immunoglobulin enhancers induces lymphoid malignancy in transgenic mice. Nature. 1985;318:533-538.

20. Schmitt CA, Rosenthal CT, Lowe SW. Genetic analysis of chemoresistance in primary murine lymphomas. Nat Med. 2000;6:1029-1035.

21. Lindemann RK, Newbold A, Whitecross KF, et al. Analysis of the apoptotic and therapeutic activities of histone deacetylase inhibitors using a mouse model of B cell lymphoma. Proc Natl Acad Sci U S A. 2007;104:8071-8076.

22. Scott CL, Schuler M, Marsden VS, et al. Apaf-1 and caspase- 9 do not act as tumor suppressors in myc-induced lymphomagenesis or mouse embryo fibroblast transformation. J Cell Biol. 2004; 164:89-96.

23. Schmitt CA, Fridman JS, Yang M, et al. A senescence program controlled by $\mathrm{p} 53$ and $\mathrm{p} 16 \mathrm{INK} 4 \mathrm{a}$ contributes to the outcome of cancer therapy. Cell. 2002;109:335-346.

24. Nebbioso A, Clarke N, Voltz E, et al. Tumor-selective action of HDAC inhibitors involves TRAIL induction in acute myeloid leukemia cells. Nat Med. 2005; 11:77-84.

25. Insinga A, Monestiroli S, Ronzoni S, et al. Inhibitors of histone deacetylases induce tumor-selective apoptosis through activation of the death receptor pathway. Nat Med. 2005;11:71-76.

26. Muzio M, Chinnaiyan AM, Kischkel FC, et al. FLICE, a novel FADD-homologous ICE/CED-3like protease, is recruited to the CD95 (Fas/ APO-1) death-inducing signaling complex. Cell. 1996;85:817-827.

27. Johnstone RW, Ruefli AA, Lowe SW. Apoptosis: a link between cancer genetics and chemotherapy. Cell. 2002;108:153-164.

28. Henderson C, Mizzau M, Paroni G, Maestro R, Schneider C, Brancolini C. Role of caspases, Bid, and $\mathrm{p} 53$ in the apoptotic response triggered by histone deacetylase inhibitors trichostatin- $A$ (TSA) and suberoylanilide hydroxamic acid (SAHA). J Biol Chem. 2003;278:12579-12589.

29. Rubinsztein DC, Gestwicki JE, Murphy LO, Klionsky DJ. Potential therapeutic applications of autophagy. Nat Rev Drug Discov. 2007;6:304312.

30. Shao Y, Gao Z, Marks PA, Jiang X. Apoptotic and autophagic cell death induced by histone deacetylase inhibitors. Proc Natl Acad Sci U S A. 2004:101:18030-18035.
31. Mizushima N. Methods for monitoring autophagy Int J Biochem Cell Biol. 2004;36:2491-2502.

32. Giles F, Fischer T, Cortes J, et al. A phase I study of intravenous LBH589, a novel cinnamic hydroxamic acid analogue histone deacetylase inhibitor in patients with refractory hematologic malignancies. Clin Cancer Res. 2006;12:4628-4635.

33. Peart MJ, Tainton KM, Ruefli AA, et al. Novel mechanisms of apoptosis induced by histone deacetylase inhibitors. Cancer Res. 2003;63: 4460-4471.

34. Ruefli AA, Ausserlechner MJ, Bernhard D, et al. The histone deacetylase inhibitor and chemotherapeutic agent suberoylanilide hydroxamic acid (SAHA) induces a cell-death pathway characterized by cleavage of Bid and production of reactive oxygen species. Proc Natl Acad Sci U S A. 2001;98:10833-10838.

35. Rosato RR, Almenara JA, Dai Y, Grant S. Simultaneous activation of the intrinsic and extrinsic pathways by histone deacetylase (HDAC) inhibitors and tumor necrosis factor-related apoptosisinducing ligand (TRAIL) synergistically induces mitochondrial damage and apoptosis in human leukemia cells. Mol Cancer Ther. 2003;2:12731284.

36. Bernhard D, Ausserlechner MJ, Tonko M, et al Apoptosis induced by the histone deacetylase inhibitor sodium butyrate in human leukemic lymphoblasts. FASEB J. 1999;13:1991-2001.

37. Garcia-Calvo M, Peterson EP, Leiting B, Ruel R, Nicholson DW, Thornberry NA. Inhibition of human caspases by peptide-based and macromolecular inhibitors. J Biol Chem. 1998;273:3260832613.

38. Fadeel B, Ottosson A, Pervaiz S. Big whee keeps on turning: apoptosome regulation and its role in chemoresistance. Cell Death Differ. 2008; 15:443-452.

39. Schafer ZT, Kornbluth S. The apoptosome: physiologic, developmental, and pathologic modes of regulation. Dev Cell. 2006;10:549-561.

40. Soengas MS, Capodieci P, Polsky D, et al. Inactivation of the apoptosis effector Apaf- 1 in malignant melanoma. Nature. 2001;409:207-211.

41. Jia L, Srinivasula SM, Liu FT, et al. Apaf-1 protein deficiency confers resistance to cytochrome cdependent apoptosis in human leukemic cells. Blood. 2001;98:414-421.

42. Wolf BB, Schuler M, Li W, et al. Defective cytochrome c-dependent caspase activation in ovarian cancer cell lines due to diminished or absent apoptotic protease activating factor-1 activity. J Biol Chem. 2001;276:34244-34251.

43. Janssen K, Pohlmann S, Janicke RU, Schulze-Osthoff K, Fischer U. Apaf-1 and caspase- 9 deficiency prevents apoptosis in a Bax-controlled pathway and promotes clonogenic survival during paclitaxel treatment. Blood. 2007; 110:3662-3672.
44. Peltenburg LT, de Bruin EC, Meersma D, Smit NP, Schrier PI, Medema JP. Expression and function of the apoptosis effector Apaf- 1 in melanoma. Cell Death Differ. 2005;12:678-679.

45. Allen JD, Zhang XD, Scott CL, Boyle GM, Hersey P, Strasser A. Is Apaf- 1 expression frequently abrogated in melanoma? Cell Death Differ. 2005;12:680-681.

46. Ekert PG, Read SH, Silke J, et al. Apaf-1 and caspase- 9 accelerate apoptosis, but do not determine whether factor-deprived or drug-treated cells die. J Cell Biol. 2004;165:835-842.

47. Marsden VS, Kaufmann T, O'Reilly LA, Adams JM, Strasser A. Apaf-1 and caspase- 9 are required for cytokine withdrawal-induced apoptosis of mast cells but dispensable for their functional and clonogenic death. Blood. 2006;107: 1872-1877.

48. Marsden VS, O'Connor L, O'Reilly LA, et al. Apoptosis initiated by $\mathrm{Bcl}-2$-regulated caspase activation independently of the cytochrome c/Apaf-1/ caspase-9 apoptosome. Nature. 2002;419:634637.

49. Galluzzi L, Vicencio JM, Kepp O, Tasdemir E, Maiuri MC, Kroemer G. To die or not to die: that is the autophagic question. Curr Mol Med. 2008;8: 78-91.

50. Carew JS, Nawrocki ST, Kahue CN, et al. Targeting autophagy augments the anticancer activity of the histone deacetylase inhibitor SAHA to overcome Bcr-Abl-mediated drug resistance. Blood. 2007:110:313-322.

51. Mathew R, Karantza-Wadsworth V, White E. Role of autophagy in cancer. Nat Rev Cancer. 2007;7: 961-967.

52. Kroemer G, Jaattela M. Lysosomes and autophagy in cell death control. Nat Rev Cancer. 2005;5: 886-897.

53. Amaravadi RK, Thompson CB. The roles of therapy-induced autophagy and necrosis in cancer treatment. Clin Cancer Res. 2007;13:72717279.

54. Scarlatti F, Bauvy C, Ventruti A, et al. Ceramidemediated macroautophagy involves inhibition of protein kinase $B$ and up-regulation of beclin 1 . J Biol Chem. 2004;279:18384-18391.

55. Ravikumar B, Vacher C, Berger Z, et al. Inhibition of mTOR induces autophagy and reduces toxicity of polyglutamine expansions in fly and mouse models of Huntington disease. Nat Genet. 2004; 36:585-595.

56. Maiuri MC, Le Toumelin G, Criollo A, et al. Functional and physical interaction between $\mathrm{Bcl}-\mathrm{X}(\mathrm{L})$ and a $\mathrm{BH} 3-$ like domain in Beclin-1. EMBO $\mathrm{J}$. 2007;26:2527-2539.

57. Amaravadi RK, Yu D, Lum JJ, et al. Autophagy inhibition enhances therapy-induced apoptosis in a Myc-induced model of lymphoma. J Clin Invest. 2007; 117:326-336. 